\title{
THE USE OF EMPIRICAL DATA IN FORMULATING BANKRUPTCY POLICY
}

\author{
Teresa A. Sullivan, * \\ ELIZABETH WARREN,** \\ AND JAY LAWRENCE WESTBROOK***
}

INTRODUCTION

The most significant thing about the role of empirical research in bankruptcy policy has been its insignificance. Just as Sherlock Holmes began with what the dog did in the night ("nothing")," we must begin with the striking fact that empirical research has played almost no role in the development of bankruptcy policy. ${ }^{2}$ Since the need for empirical research ${ }^{3}$ in

\section{Copyright $\odot 1987$ by Law and Contemporary Problems}

The authors acknowledge the assistance of Grant No. R-0015 (Urban Studies Program) and No. R-0009 (National Policy Program) from the Lyndon B. Johnson School of Public Affairs, Policy Research Institute of the University of Texas. Completion of this article was facilitated by support from National Science Foundation Grant No. SES-8310173. Any opinions, findings, conclusions, and recommendations expressed in this publication are those of the authors and do not necessarily reflect the views of the National Science Foundation.

We acknowledge the helpful research assistance of James Cochran. We are grateful once again to our generous colleagues who spent their valuable time to offer suggestions, including David Keyser, Douglas Laycock, Lynn LoPucki, Stewart Macaulay, Bruce H. Mann, John Robertson, and Mark Yudof. In accordance with scientific custom, the authors of this article are listed in alphabetical order to indicate their equal contributions.

- Professor of Sociology and Faculty Research Associate, Population Research Center, University of Texas at Austin; B.A. 1970, Michigan State University; A.M. 1972, Ph.D. 1975, University of Chicago.

** Professor of Law and Jay H. Brown Centennial Faculty Fellow, University of Texas at Austin; B.S. 1970, University of Houston; J.D. 1976, Rutgers College of Law (Newark).

*** Andrews \& Kurth Professor of Law, University of Texas at Austin; B.A. 1965, J.D. 1968, University of Texas at Austin.

1. A.C. Doyle, Silver Blaze, in The Complete Sherlock Holmes 347 (1927).

2. See Discussion, Law AND Contemp. Probs., Autumn 1977, at 129 (statement of Philip Shuchman) [hereinafter Discussion]. Professor Shuchman explains how the OMB viewed empirical research:

We had been in business in the [Bankruptcy] Commission for perhaps three months of what was to be an almost two-year undertaking - a year and a half of research and half a year of writing. At that point a man from the Office of Management and Budget came to visit us. Without going through the poetics of his statement, what he put to us was the following question: "What is going to be in your final report? Once you tell me this"- he was ready with his pencil-"we'll work backwards from there."

Id. Of course, from the start, Congress has used data that could be called empirical. See Sullivan, Warren \& Westbrook, Limiting Access to Bankruptcy Discharge: An Analysis of the Creditors' Data, 1983 WIS. L. REv. 1091, 1101 [hereinafter Sullivan, Warren \& Westbrook] (Congress sent out more than 15,000 letters and collected more than 20,000 constituent comments before formulating the 1903 amendments to the Bankruptcy Act.). In saying that empirical data have played a very small part in making bankruptcy policy, we are not unmindful of the impact of the Purdue University study. Credit Research Center, Krannert Graduate School of Management, Purdue University, 
this field is generally acknowledged, ${ }^{4}$ we should try to understand why it has played so small a role and how it might someday achieve its appropriate place in bankruptcy policymaking.

Some skeptics will claim that the explanation is simple: Empirical research is little used in all legislative policymaking because its value is overstated and its application problematic. This response fails in its premise. Empirical research is constantly used as the basis for the formation or amendment of statutes in a host of legislative areas. The regulation of commercial activity is a field especially notable for its consistent reliance on the products of empirical research. Examples include monetary policy, trade policy, tax policy, and banking and currency regulation. ${ }^{5}$ The skeptics do not think of the data that are routinely used in these fields as "empirical." When the skeptics speak of empirical research, they are thinking of a threadbare academic cadging a grant to stand on a corner with a clipboard asking short people if they would like to be taller.

Our thesis is that empirical research is vitally needed in the formation of bankruptcy policy and that it is possible to develop empirical data that will become an indispensable part of that process. We believe that this result depends upon the regular collection of bankruptcy data by the courts and the Administrative Office of the Courts, and the subsequent dissemination of those data to the academic community, on the models presented by the United States Census Bureau, the Bureau of Labor Statistics, and other datagathering agencies. Such an approach would not be practical with most types of civil litigation; but bankruptcy is unique in its requirement that every petitioning debtor file voluminous schedules that set forth detailed information about his financial affairs and recent financial history. This data source is much like those used for other regularized data gathering. As a result, a large amount of important statistical information could be drawn directly from these schedules-information that would inform and guide further empirical studies. While there are many aspects of bankruptcy that will require specific, one-shot studies to uncover, the usefulness of those data will always be limited until they are linked to general data collected on a regular basis. Because the information necessary for a broad data base is

Consumer Bankruptcy Study (1982) [hereinafter Purdue Study]. While that study was used as ammunition in the debate over the 1984 amendments to the Bankruptcy Code, its recommendations were severely watered down. It is also true that The Brookings Institution study had some impact on the Bankruptcy Reform Act of 1978, 11 U.S.C. $\$ 101$ (1982) [hereinafter the Bankruptcy Code]. For example, it had an obvious influence on the establishment of the experimental United States Trustee system, but its overall effect on the Bankruptcy Code seems to have been much less than one would have thought. D. Stanley \& M. Girth, Bankruptcy: Problem, Process, Reform 115 \& Table 6-3 (1971) [hereinafter BROOKINGS REPORT].

3. Although any product of observation or experiment might be called empirical, we will usually use the word to refer to data gathered systematically. See infra note 22 and accompanying text.

4. See, e.g., H.R. Doc. No. 137, 93d Cong., 1st Sess., pt. 1, at 110-11 (1973); Discussion, supra note 2, at 123, 127; Shuchman, Theory and Reality in Bankruptcy: The Spherical Chicken, LAw \& CoNTEMP. Probs., Autumn 1977, at 66, 68.

5. See infra notes 95-103. 
already being provided on fairly standardized forms, we believe that the data could be made available in computer-readable form at a reasonable cost.

\section{II}

\section{The Role of Empirical Data in Policymaking Generally}

In this article, we address the specific topic posed by the editor, the role of empirical research in bankruptcy policymaking. There are larger questions about the relationship between empirical research and political decisionmaking and about the place of empiricism in the study of human conduct and institutions. While these questions are fascinating and important, they are not our subject on this occasion. ${ }^{6}$

Nonetheless, the reader is entitled at the outset to have some notion of our general views about the place of empirical work in the study and the ordering of human affairs. Two of us are legal academics who spend most of our time writing and lecturing about bankruptcy doctrine in reasonably conventional terms. The third is a social scientist whose work is primarily in the analysis of the "hard" data of demography. None of us imagines that human conduct is reducible to mathematical formulae or dreams of the day when horn-rimmed researchers will replace politicians. We do not believe that empirical data will ever displace hunch or prejudice. We recognize that empirical data will never provide "answers" to policy questions, because the data will never be complete and because such questions always require normative judgments.

We also understand that there are those who could not be persuaded by any data. They can be found on the political left or right; they share the belief that they already possess the truth and have no need for further information. For these people, the data will not affect the debate. Still others have overriding concerns that cause them to argue for predetermined positions regardless of what the empirical data may show.

But we believe that knowledge is better than ignorance and that data gathered systematically and carefully will raise the level of policy debate and improve its conclusions. Even if a storehouse of data does not provide answers, it can eliminate arguments or alternatives that would seem plausible in its absence. If the narrowing of the opportunities for error is a modest goal, it is still an important one. In any policy discussion, even the dogmatic are forced to give lip service to the force of evidence, and the fair-minded not infrequently swing the vote. Moreover, the ready availability of reliable data may serve the salutary purpose of putting some ideologues on the defensive. The creation of a more reliable and accurate base of data about the operation of the bankruptcy laws would improve, if not perfect, our national bankruptcy policy.

6. See, e.g., Simon, Human Nature in Politics: The Dialogue of Psychology with Political Science, 79 AM. Pol. Sci. Rev. 293 (1985). 
III

\section{The Need for Empirical Research in Formulating a National BANKRUPTCY POLICY}

\section{A. Normative and Factual Assumptions Underlying Bankruptcy Policy}

Bankruptcy policy ${ }^{7}$ necessarily emerges from a marriage of factual assumptions and normative decisions, although the factual premises are rarely separated from the normative in the discussion of bankruptcy policy. The normative aspects of bankruptcy policy often seem dominant. This normative domination is reflected in the diversity among insolvency laws that exist in various countries. While almost all societies with a substantial private sector have a legal regime addressing the possibility of economic collapse, the rules that govern insolvency are very different around the world. Even in societies with similar economies, there are substantial differences that reflect differing normative judgments. It is not a difference in economic circumstances that dictates that a director of a bankrupt French company is more likely to go to jail than his American counterpart.8

Nonetheless, the formulation of bankruptcy policy necessarily involves a host of factual assumptions as well. Fundamental bankruptcy policies for both consumers and businesses are based on assumptions of fact about the behavior of debtors and creditors, credit markets, attorneys, landlords, equity holders, tort victims, trust donors, repo purchasers, stockbrokers, codebtors, shopping center lessors, labor unions, warehousemen, taxing authorities, layaway purchasers, accountants, farmers, foreign representatives, insiders, outsiders, and the rest of the cast. Some of these assumptions are tested, and some are not; likewise, some are accurate, and some undoubtedly are not.

Yet, debates about bankruptcy policymaking rarely call for empirical data to enlighten the debate. Nor do the debaters suggest that the debates should be suspended until someone (even if not the author) can get a look at what is going on in the world. Young scholars (presumably those with more time and energy than senior experts) are not exhorted to gather the necessary data. Instead, the dialogue continues with the youngest and least experienced trading policy suggestions and pronouncements with the oldest and most wizened-and no one suggests that the game is somewhat suspect without

7. Legislative policymaking is the focus of this article. Of course, the bankruptcy courts also develop much of our bankruptcy policy. We discuss the use of empirical data in legislative policymaking rather than in case law, not because we think empirical data have no appropriate role in judicial decisions, but because legislative policymaking has an overwhelming impact on the resulting policy decisions. The legislative process deals with different problems, different evidence, and different degrees of freedom in formulating solutions than does the judicial process. Separate study of the issues raised and data that are needed for judicial decisionmaking seems most appropriate.

8. See, e.g., $1 \mathrm{~J}$. Dalhuisen, Dalhuisen on International Insolvency and Bankruptcy 83.02 [2], at 2-247 to 2-248 (1986). Another key difference is the discharge, which is a central feature of United States bankruptcy law but is unknown in most of Europe. Id. $\$ 1.07[1]$, at 2-132.2 to 2-132.4. A third distinction that seems to have a normative aspect lies in the extent to which creditor approval of a composition is required: In most western European countries, majority creditor approval is required, while in France and the United States certain procedures require no creditor approval at all. See id. \$ 2.01[2][e], at 2-148.16 to 2.148.17. 
some empirical bases from which to argue. In short, there is an intellectual failure in bankruptcy policy debates.

One consequence of this failure is that it remains eminently respectable when discussing bankruptcy policy to ignore missing empirical data and to pass over the few data that are available. So long as the debates can continue unabated-and law review articles, newspaper interviews, and congressional testimony can proceed with professional aplomb-then there is little incentive to incur the costs of weekends away from home to collect empirical data.

The failure of academic policy-advisers and policymakers to insist on development of empirical data as an essential component of developing bankruptcy policy has an even more debilitating effect on the policy debates. As the policy debates continue unimpeded by concern about the facts, the questions discussed necessarily do not highlight their empirical assumptions. In order not to call attention to the highly speculative nature of a debate that should be well founded in empirical observations, empirical postulates are almost never singled out. Issues are framed and discussed without separating their empirical and normative parts. As Orwell said, when we are hiding something, our language reflects our state of mind and we become "like a cuttlefish squirting ink."9 When the empirical bases for policy positions are camouflaged by normative positions, the empirical questions are not clearly formulated and no agenda for empirical study is produced.

Another consequence of the blending of empirical and normative issues is that the policymaking process itself becomes unsound. The debate suffers from a failure to join issue: Disputants are always trying to hit a moving target. When normative debates are heated, empirical assumptions are traded back and forth both to fuel and to diffuse the debate. When empirical issues move into the spotlight, they are shaped and controlled by their normative components. The failure to clarify the debate between its normative and empirical aspects leads to a rambling, amorphous exchange in which many questionable conclusions-both normative and empirical-slide through without careful examination. ${ }^{10}$

This fuzzy debate contributes to the dearth of useful empirical data. Because empirical and normative questions are deeply intertwined, it is easy to blend the two and to ask empirical data to yield answers to questions laced with normative assumptions. When the answers are not forthcoming, the questioner is faced with an inescapable conclusion: Empirical research cannot answer the questions asked.

9. G. Orwell, Politics and the English Language, in Shooting an Elephant and Other Essays 89 (1950).

10. The debates preceding the 1978 Code over appropriate personal exemption levels appear to have been resolved by "compromise," but with little serious joinder of issue as to what a family needed as part of its fresh start. A heated but vague exchange prevailed, with only fleeting references to the Consumer Price Index, the current poverty level, the Bureau of Labor Statistics standard budget for a family of four, or any other statistical generalizations. See Warren, Reducing Bankruptcy Protection for Consumers: A Response, 72 Geo. L.J. 1333, 1351 (1984). 
An illustration in business bankruptcy would be: How many reorganizations are successful? Before spending large amounts of money on a study of this question, one had best carefully define success. Is confirmation of a plan enough, or must the business complete payments under the plan? Does a business that pays fifty percent of its debt before defaulting and closing represent a more successful reorganization than one that completes its plan by paying thirty percent and remains in business at least three years thereafter? Are jobs saved as important as percentage of debt paid? It is not merely important that the researcher identify the normative and empirical issues clearly. It is necessary to identify the right questions-or at least the most useful ones-in advance, so that scarce resources will not be squandered.

\section{B. The Need for Empirical Data}

Although bankruptcy policymaking interweaves empirical and normative elements, the two are rarely distinguished and the empirical assumptions are rarely tested. Yet, inaccurate factual assumptions can result in policies that are at best ineffective in accomplishing their normative goals and at worst exacerbate the problems they attempt to correct. The point here is not to argue that all factually based assumptions must be verified through rigorous social science methods, but simply to suggest that factual assumptions pervade the development of bankruptcy policy and their accuracy is crucial to sensible policy decisions.

Two examples, one from consumer bankruptcy and one from business bankruptcy, may illustrate the importance of using empirical data and the dangers of ignoring the empirical bases of policy formulations. In consumer bankruptcy, the notion of the debtor as an economically rational actor has pervaded the literature, ${ }^{11}$ the analysis, ${ }^{12}$ the congressional inquiry,,$^{13}$ and the consequent thrust of the Bankruptcy Code. So, for example, economic incentives were built into the 1978 Bankruptcy Code to "encourage debtors to select chapter 13."14 In 1984, the Code was amended so that the economic incentives would encourage more debtors at the margin to elect chapter 13.15 Many of the resulting Code enactments, such as reductions of federal

11. See, e.g., Purdue Study, supra note 2; Vukowich, Reforming the Bankruptcy Reform Act of 1978: An Alternative Approach, 71 GEo. L.J. 1129 (1983) [hereinafter cited as Vukowich, Alternative].

12. See, e.g., Mechling, Financial Markets, Default, and Bankruptcy: The Role of the State, LAw \& Contemp. Probs., Autumn 1977, at 13. See also the critical comments of Shuchman, supra note 4.

13. See, e.g., Bankruptcy Reform Act of 1978: Hearings Before the Subcomm. on Courts of the Senate Comm. on the Judiciary, 97th Cong., 1st Sess. 13, 21 (1981) (prepared statement of Andrew F. Brimmer) [hereinafter Hearings]; id. at 51, 54 (prepared statement of Claude Rice, Alvin O. Wiese, Jr., and Jonathan M. Landers); id. at 223 (questions asked by Senator Heflin).

14. Vukowich, Alternative, supra note 11 , at 1137.

15. The 1984 amendments curb such consumer debtor protections as the size of exemptions and the permissibility of stacking; they followed a media and lobbying blitz supported by the consumer credit industry which demanded that more debtors be denied access to chapter 7 and be "encouraged" to take chapter 13. See Countryman, Bankruptcy and the Individual Debtor-And a Modest Proposal to Return to the Seventeenth Century, 32 CATH. U.L. REv. 809, 820-27 (1983); Warren, supra note 10 , at 1333-34. 
property exemptions in chapter $7^{16}$ or the 1978 provisions for enhanced discharges in chapter 13,17 stem from the unarticulated assumption that debtors will behave according to an economic model. This assumes that there are debtors at the margin-to put it in economic lingo-who will alter their behavior according to the economic "incentives" of the Bankruptcy Code.

The assumption that such debtors exist in significant numbers, behave according to the model, and will respond to statutory changes is factual. It is also unverified. An empirical study might verify this assumption, or such a study might reveal that only a handful of debtors behaved according to the model, perhaps because debtors were poorly informed about relevant legal and economic factors or because other factors-such as the emotional commitment to avoid "real bankruptcy" or the fear of continued court supervision-swamped the debtors' decisionmaking processes. ${ }^{18}$

If the economic model is empirically accurate, then the Bankruptcy Code's economic incentives may accomplish the goal of encouraging more consumers in bankruptcy to select chapter 13. If, however, the model is inaccurate, then the statutory economic incentives may have a negligible effect on debtor choices and may be harmful to other normative goals. The broad discharge in chapter 13, for example, is justified as an incentive. ${ }^{19}$ If this incentive element is inconsequential to all but a handful of debtors, the cost of injury to normative goals arguably makes the broad discharge indefensible. The broader discharge in chapter 13 may outrage many in the community (e.g., discharging a victim's tort judgment against a man who attacked her with a claw hammer). ${ }^{20}$ This outrage is too high a price if the incentive is ineffective in affecting the chapter 7/chapter 13 choice.

On the business side, the policies developed to accommodate business failures are based on a similar intertwining of factual and normative assumptions. One unspoken, but key, factual assumption underlying chapter 11 is that businesses, once permitted to delay debt payments or to discharge debt and retain their corporate charter, can fairly often rise phoenix-like from their failures and resume making socially useful contributions to the business community. This empirical assumption combines with normative judgments to produce Bankruptcy Code provisions that seriously compromise the contractual and property rights of creditors.

16. Bankruptcy Amendments and Federal Judgeship Act of 1984, Pub. L. No. 98-353, § 306, 98 Stat. 333, 353 (1984).

17. 11 U.S.C. \& 1328(a) (1982).

18. Some economists could incorporate these issues as well by labeling the emotional commitment a "taste" and the relief from creditors as "psychic income." Since "tastes" and "psychic income" are difficult to measure prospectively, this reduces the predictive power of the model either to tautology or to post hoc explanation. See T. Parsons \& N. Smelser, Economy and Society 279 (1956).

19. See Vukowich, Allernative, supra note 11 , at 1137.

20. "Brutal, Well-heeled Assailant Uses Bankruptcy Ploy," Dallas Times Herald, March 20, 1982, at A-31 (discharge of victim's tort judgment against debtor who attacked her with a claw hammer). 
An empirical study might confirm that a significant number of debtors emerge from chapter 11 reorganizations as stable employers, reliable debtors, and continuing producers of goods or services. An empirical study might instead indicate that only a handful of debtors entering chapter 11 emerge intact and that the sole issue in the vast majority of chapter 11 cases is whether the dissolution will occur now or later. If the latter hypothesis were borne out by empirical studies, further empirical questions and a host of normative questions would come into play in reshaping bankruptcy policy. Even the most basic assumption of our business bankruptcy policies-that the large, expensive process of untying legal obligations in reorganization does, in fact, yield substantial social benefits-has never been seriously tested. ${ }^{21}$

\section{IV}

\section{The Need for Systematic Empirical Data}

"Empirical" data come in many shapes and varieties. It is important to begin by identifying the various types and examining the strengths and weaknesses of each type. Generally, data are classified by the way in which they are gathered. Data can be gathered systematically or unsystematically. Systematic data can be divided into episodic data, which are the product of a discrete study, and routine data, which are gathered on a regular basis, usually by a government department. Unsystematic data can be divided into two principal categories, anecdoctal and expert. Another kind of data, qualitative data, is usually unsystematic, and we discuss it under that heading as well.

Because all data have flaws, there are only degrees of confidence in the use of any data. We first describe the generally accepted standards for all types of data. We then apply them to the unsystematic data ordinarily used in formulating bankruptcy policy and discuss the deficiencies. In a later section, we discuss the problems in using systematic data under current conditions.

\section{A. Criteria for "Good" Data}

Empirical data constitute evidence that will be woven into the policymaking debate. Just as there are many types of evidence, there are

21. The major study done at The Brookings Institution suggests, somewhat opaquely, that well over half of their chapter XI cases with confirmed plans had failed within two years of confirmation. Brookings REPORT, supra note 2, at 115 \& Table 6-3. The study found that plans were confirmed in eighty-six percent of the chapter XI cases studied. Id. at 140. This high level of confirmations may not have been typical or may have changed since the mid-sixties, when the study was done. See In re Petur U.S.A. Instrument Co., 35 Bankr. 561, 564 (Bankr. W.D. Wash. 1983) (less than four percent of chapter 11 cases in that district resulted in confirmed plans). Professor LoPucki has done a ground-breaking study in Kansas City. LoPucki, The Debtor in Full Control-Systems Failure Under Chapter 11 of the Bankruptcy Code?, 57 AM. BANKR. L.J. 99 (1983). In that study, he found that about twenty-seven percent of the businesses in chapter 11 succeeded in getting a plan confirmed and remaining in business through the date the study was done. Id. at 107. This result seems roughly comparable to the findings of the BROOKINGs REPORT, supra note 2. While this work points us in the right direction, we are unable to extrapolate its conclusions to the entire country. It is quite possible that the Western District of Washington is highly aberrational and Kansas City is typical, but the present evidence does not permit us to be confident of that conclusion. 
many types of data. Rules govern the use of evidence in the courtroom. In other disciplines, accepted research methods govern the collection and interpretation of data. Among policymakers, however, there is much less consensus about "rules" of evidence. For example, testimony in legislative hearings offers a wide variety of evidence that represents a considerable (although unknowable) range of accuracy and representativeness.

Empirical data on bankruptcy are appropriately tested by the same criteria used for other types of empirical data. These criteria may be summarized as generalizability, verifiability, and interpretability. ${ }^{22}$ An examination of the weaknesses of data under each criterion gives some idea of their appropriate uses-and limitations-in shaping bankruptcy policy.

Generalizability is the quality of data that permits one to make inferences from the data observed to the data that are unobserved-from the part to the whole. A familiar example of this is the medical technician's generalization about all of one's blood based upon only a small sample of it. Data that are generalizable permit answers concerning the averages or central tendencies of results as well as the range of deviations from the norm. ${ }^{23}$ For example, one could analyze the mean amount of unsecured debt and its standard deviation in a sample of debtors to derive useful information about all debtors in bankruptcy. On the other hand, if a researcher studying consumer bankruptcy draws a biased sample of debtors consisting only of the poorest entering bankruptcy, then any inferences drawn from the data could not be generalized to all debtors in bankruptcy.

Verifiability is a quality of data that permits someone other than the original observer or experimenter to "cross-examine" the data and to arrive at similar (or different) results. Verifiability implies not only that a second observer would reach the same conclusion, but also that the entire study could be replicated and would yield similar results. ${ }^{24}$ For example, a technician who sampled someone's blood with a contaminated syringe would not produce reliable data about the blood. Any subsequent sample using a different-presumably cleaner-syringe would not be likely to yield the same results. Similarly, in bankruptcy policy, differing definitions of "business bankruptcy" have tended to confuse findings concerning both corporate and individual bankruptcies. ${ }^{25}$ For example, an observation of changes in rates of

22. We have used these terms to subsume many more specific terms used to describe desirable properties of data. K. Bailey, Social Research Methods 56-66 (1978), identifies additional subcriteria such as face validity, id. at 58 ; criterion validity, id. at 58-59; construct validity, id. at 59-60; and internal and external validity, id. at 60-61 [hereinafter $\mathrm{K}$. BaILEY].

23. Generalizability usually relies on the principles of statistical inference; from this, many have concluded that empirical data must be "quantitative." It is not necessarily true that generalizable data must be quantitative, but it is easier to demonstrate the generalizability of quantitative data.

24. This concept connotes "reliability," a term often used in test constructions to indicate that an item repeatedly measures what it is supposed to measure. K. BAILEY, supra note 22, at 61-63. Verifiability also connotes the related idea of "validity," a term that means that a measure is a true indicator of what it is supposed to indicate, and not a measure of something else. Id. at 56-61.

25. See infra note 90 . 
business bankruptcies based on unspecified changes in their classification criteria would not be verifiable.

Interpretability refers to the quality of the data that permits findings to be incorporated into a more general, abstract framework. A sample of blood is generalizable to all of a person's blood, but analysis of the sample-for example, a white blood cell count-is interpreted within a framework that defines blood count levels as "normal," "too high," and "too low." In addition, a count that is "too high" may then generate alternative hypotheses concerning disease, infection, etc. These hypotheses can then be progressively eliminated with additional tests.

Most data can be interpreted within many frameworks, although some frameworks require a number of logical inferences. For example, the annual number of filings in consumer bankruptcy may be readily interpreted within a calculation of a judge's caseload, such as proportion of a judge's time spent on chapter 11 cases. This estimation requires an interpretive framework that includes assumptions about how long each case takes, the geographic distribution of the cases, etc. It requires many more inferences, however, to interpret data for certain other conclusions. For example, to determine that the number of bankruptcy filings is "too large" (given what standard?) or that it "represents substantial abuse" (given what interpretive framework?) demands an abundance of factual inferences interlaced with a number of normative conclusions.

These three criteria are not necessarily distinct from one another. For example, generalizability is closely linked to interpretation. Generalizability of findings from large, representative samples depends in particular upon the interpretive framework of the science of statistics and in general upon the research methods of the various social science disciplines. In addition, other interpretive frameworks may come into play. ${ }^{26}$ These frameworks require the somewhat backwards-sounding logic of the sciences: No hypothesis is ever "proven," but competing hypotheses can be disproven. In the same manner, while no research methodology can prove the uniquely "right" way to collect or interpret data, it can demonstrate why a number of techniques are wrong.

One consequence of this type of reasoning is that a research method considered adequately interpretable twenty or even ten years ago may now be thought ambiguous or erroneous, and the results achieved through the use of the method become suspect. As the interpretive frameworks multiply both in terms of sophistication and number, the methods used in assessing generalizability and verifiability must also change. Once empirical data are derived, they are not simply tested and categorized as fact; for continuing vitality, they must be constantly reevaluated against state of the art tests.

26. For example, bankruptcy data may be interpreted by sociologists within the theoretical framework that identifies factors in migration or within a social stratification framework. These interpretive frameworks are sometimes called "paradigms." See generally T. Kunn, The Structure of Scientific Revolutions (1962); G. Ritzer, Sociology: A Multiple Paradigm Science (1975). 


\section{B. The Weaknesses of the Data We Now Use}

With these criteria for evaluating data in mind, we can examine the unsystematic data most widely used in formulating bankruptcy policy. To the extent that bankruptcy policy has been shaped by empirical observations, the data have tended to be anecdotes, expert opinion based on years of observation, and qualitative data. Such unsystematic data can be distinguished from systematic data in that the former are rarely collected according to a predetermined research design. Instead, unsystematic data are fortuitously "collected" as they come to the attention of the person who passes them on.

1. Anecdotes. The anecdote or "war story" is empirical because it originates from someone's observation (although it may be retold second- or third-hand). Anecdotes are remembered and retold, often blurring the details to emphasize the most memorable features of the story. The reliability of such data is difficult to establish, and it is noteworthy that in a courtroom this type of data is carefully governed by rules of evidence. In legislative hearings and similar fora, where the "rules" of evidence are less restrained, anecdotes are usually remembered or retold for a purpose-that is, they are used to illustrate an exceptional incident or set of facts. Anecdotes rarely portray the "average" case.

Heightened sensitivity affects the perception of anecdotal evidence. ${ }^{27}$ When one wants to buy a Toyota, Toyotas on the street are noted with much greater regularity. When a woman is pregnant, everyone tells her stories of calamitous pregnancies, birth defects, and mysterious ailments of pregnant women. In the same way, when a bankruptcy policy issue makes the news, it will "jog the memory" of nearly everyone to recount a favorite anecdote. If the newsworthy issue is "abuse," everyone will have an abuse story to relatebut the actual prevalence of abuse will not have changed, nor will its incidence be any better known. ${ }^{28}$

Folklorists are occasionally successful in tracking down the initiating event in an anecdote, but anecdotes are usually impossible to verify (especially second- or third-hand ones). ${ }^{29}$ One common theme in consumer bankruptcy "war stories" is the clever, unscrupulous debtor who leaves hundreds of creditors unable to touch his palatial homestead, luxury automobiles, and

27. When this heightened sensitivity occurs in the subject of the research, it is termed "reactivity." The famous Hawthorne Effect is an example of a reactive effect of research. S. Rothlisburger \& W. Dickson, Management and the Worker (1939). We speak here of the heightened sensitivity of the policymaker or consumer of empirical research.

28. "Abuse" had always been a consumer issue until the unions complained about solvent companies using bankruptcy to avoid labor contracts, and personal injury lawyers railed about the asbestos companies. Otherwise, newsworthy business bankruptcies are usually calamities, while consumer bankruptcies are outrages.

29. Of course, tracing the origin of a dubious statistic may also be difficult. D. Hauck, Statistical Literacy: A Guide to InTerpretation 20 (1979), gives the example of a syndicated columnist who first reported, and then unsuccessfully tried to verify, a statistic that 500,000 Vietnam veterans had attempted suicide [hereinafter cited as D. HAUCK, LITERACY]. 
diamond jewelry. These stories are analogous to the stories about welfare recipients driving Cadillacs. ${ }^{30}$ In carrying out our own research, we have been told by court personnel of the "people who go into bankruptcy over and over again," although our systematic sample of cases revealed virtually no such debtors.

Anecdotes inevitably present the problem of verifiability: Would another observer agree on the basic "facts"? Even if an anecdote is substantially verifiable, there are no accepted rules for its interpretation.

An unusual case of verifying anecdotes occurred during recent hearings on amendments to the 1978 Bankruptcy Code. When a credit industry spokesman testified in favor of changes to the Code in order to force more bankrupt consumer debtors into chapter 13, he alleged that a significant number of debtors who could pay their debts were filing for chapter 7 liquidations rather than repaying in chapter $13 .{ }^{31}$ When the hearing committee asked for documentation, the industry spokesman eventually produced the names of five debtors who, in the view of the credit industry, were abusing the bankruptcy process. ${ }^{32}$ Chairman Rodino sent the names to the General Accounting Office (GAO) for investigation, ${ }^{33}$ prompting the GAO to conduct interviews, collect financial records, and report on these "abusers." 34 Among the five debtors, one could not work because he had muscular dystrophy and had moved his family into a trailer home with the wife's parents and sister to save on expenses. ${ }^{35}$ Another debtor had been hospitalized, and his wife had lost her job. ${ }^{36}$ Another had been in a car accident in which her uninsured car was apparently destroyed. ${ }^{37}$ The GAO's investigation verified the anecdotes of these "abusive" debtors for the

30. A call that Professor Elizabeth Warren received from a Houston Post reporter is instructive on this point. The reporter said he was doing an article on "what's going on with bankruptcies" and wanted help in finding "those bankruptcy frauds-you know, people who keep their expensive cars and fur coats after bankruptcy." He said that the attorneys and court clerks whom he had interviewed had told him about such people, but when he wanted the name of one, at that point all his informants stopped. The reporter had heard that we had been through about 1500 cases and so he was sure we could help. When Professor Warren explained that she had never encountered such a case, but would be happy to tell him about her impressions of the typical bankrupt debtor, the reported declined. The typical debtor "just isn't news." So the reporter said he would continue his search for the cheating debtor. So far as we know, no newspaper story ever emerged from this search, causing us to conclude that the reporter had been unsuccessful in his pursuit.

31. Telephone conversation between Professor Jay Westbrook and Mr. Richard Caradine, General Accounting Office (Apr. 12, 1983). Mr. Caradine noted that the industry presented examples of "rich" debtors.

32. Id.

33. Id.

34. U.S. General Accounting Office, Report to the Chairman, Comm. on the Judiciary, House of Representatives, A Profile of Selected Personal Bankruptcy Cases 1 (1983). Of the five debtors referred to the GAO, three agreed to be interviewed and two refused. Id. at 12-16. Information about the two who refused interviews was culled from the data filed with the bankruptcy petition, but it necessarily lacked the elaborating financial and social details as to what these debtors saw as the factors contributing to their bankruptcies. Id.

35. Id. at 4 .

36. Id. at 10 .

37. Id. at 6. The GAO also discovered some financial imprudence, including one couple who attributed their difficulties to the purchase of buying a car they could not afford. Id. at 4 . 
members of Congress. The senators and representatives were left to interpret for themselves the normative issue of whether each case had been properly labelled as an "abuse" of bankruptcy. ${ }^{38}$

Another characteristic of anecdotes is their lack of generalizability. Anecdotes help us to remember the exceptional or unusual cases, not the norm. (Compare what you remember about your best or worst college instructor with what you recall of the "average" college instructor.) While anecdotes do not demonstrate how frequently the portrayed event occurs, they can, nonetheless, be important in shaping policy as "horror stories" that illustrate legal loopholes or practices that outrage the public. A practice or behavior that occurs only once in a decade but is utterly reprehensible to every citizen may be worth proscribing, and an anecdote concerning the only instance of the behavior is valuable evidence for guiding that policy. ${ }^{39}$

On the other hand, because anecdotes are not generalizable, a policy response based solely on anecdotes necessarily risks disproportionate responses. A statute may deploy vast enforcement resources to prevent or punish behaviors that rarely occur.

2. The Voice of Experience. A related type of data common in congressional bankruptcy hearings is the testimony of experienced practitioners, trustees, or judges who share with Congress their firsthand experience in the bankruptcy courts. ${ }^{40}$ Although it may incorporate "war stories" as illustrations, such testimony can be distinguished from mere recounting of anecdotes by its emphasis on experience with many cases, often over a long period of time. By appearing to discern trends from a number of cases, expert testimony seems to be generalizable. And because of the eminence of the expert, such testimony meets with deference more often than with searching questions.

In terms of generalizability, however, even the most accurate and unbiased expert testimony may be misleading. For example, the testimony of a judge

38. One commentator dismisses this evidence as showing that ". . . repayment of a significant part of their obligations from liquidation of assets and from future earnings would have been possible had the alternative of bankruptcy not been available." Shepard, Personal Failure and the Bankruptcy Act of 1978, 27 J.L. \& Econ. 419, 426 n.26 (1984) [hereinafter Shepard].

39. The hearings preceding the adoption of the 1978 Code demonstrate some aggressive argumentation from anecdotal information. To persuade Congress that educational loans should not be discharged in bankruptcy, letters to senators and representatives told the story of "a graduate of a four-year state college who was employed as an Income Maintenance Specialist by the State of Vermont," and who received a discharge on " $\$ 6,130.07, \$ 5,743.30$ of which represented student loans." Report of the Committee on the Judiciary together with Separate, Supplemental, and Separate Additional Views [Including Cost Estimate of the Congressional. Budget Office] [To accompany H.R. 8200], H.R. Rep. No. 595, 95th Cong., 1 st Sess. 159 (Sept. 8, 1977). Evidently Congress was persuaded, although there have been subsequent indications that educational loan defaults were never the pervasive problem that had been depicted earlier.

40. See, e.g., Hearings, supra note 13, at 203 (statements of Bankruptcy Judges Lloyd D. George, David A. Kline, and Robert L. Hughes); id. at 274 (statement of Richard L. Levine, Director and Counsel, Executive Office for United States Trustees, U.S. Department of Justice, Washington, D.C., accompanied by Irving Picard, United States Trustee, and David Coar, United States Trustee); id. at 297 (statement of Richard Levin, attorney). 
may be entirely accurate with respect to one district but not to others (even within the same state). In addition, remembering and recounting one's own cases lead to the same problems encountered with nonexpert telling of an anecdote: Cases may be remembered because they are long, or complicated, or funny, or perfect (if rarely occurring) illustrations of a legal loophole.

Furthermore, the human tendency to muddle value orientations with "facts" (or the empirical observations with the normative judgments, to put it into the jargon of this article) may lead to testimony that is unintentionally normative rather than empirical. An example of this effect occurred in our interviews with one experienced bankruptcy judge, who told us unequivocally that he never approved reaffirmations. ${ }^{41}$ When we examined a systematic sample of his consumer bankruptcy cases, we found that he had never refused to sign a reaffirmation. This judge was neither mendacious nor misleading; rather, he "forgot" the exceptions he made from day to day in what he viewed as his general policy. The judge is much like the dieter who never, as a policy, eats sweets-except this once.

3. Qualitative Data. Some types of data are not easily measured or must be measured on a non-quantitative scale.42 "Self-discipline" or "compulsiveness" are qualities that might describe some debtors, but even trained observers might disagree with one another, after observing a section 341 meeting, on how "disciplined" the petitioners appeared to be or on how "compulsive" their spending habits were. 43 Such qualitative characterizations are often used in "explaining" consumer bankruptcy, even though they may raise more issues than they settle.

This is not to say that such data are useless; for example, much of what we know of many remote cultures is based precisely on the trained observation and interpretation of anthropologists. Just as with reading anthropology or history, however, our trust in the findings depends upon our trust in the guide. The findings are difficult in practice to verify, even if precise and correct recording techniques are used; furthermore, the data are difficult to generalize, and the principles of interpretation are subject to dispute. ${ }^{44}$

Qualitative data sometimes dress in the robes of quantitative data. By beginning with a qualitative judgment (for example, dividing the origins of statutes into their religious and common law sources ${ }^{45}$ ) and repeating the

41. 11 U.S.C. \$ 524(c) (1982), amended by Pub. L. No. 98-353, § 308(b), 98 Stat. 333, 354 (1984). Our interviews occurred before the 1984 amendments.

42. "Qualitative nominal measurement" is the term used to designate basic classifications of skin color, religion, or other properties without ordered characteristics. K. BaILEY, supra note 22, at 52-53.

43. Types of observation studies are classified in id. at 219-41.

44. Id. at 217-18.

45. In his study of Colonial American statutes, Bradley Chapin read the statutes of various colonies and then "estimated" the sources for the statutes, so that a Rhode Island statute might be described, for example, as sixty percent religious and forty percent English common law. Statutory sources for the colonies were then averaged and compared, so that the different colonies were compared on the sources of their laws. B. Chapin, Criminal Justice in Colonia America, 1606-60 (1983). 
qualitative judgment enough times to yield numbers, the ultimate analysis sometimes appears to be quantitative. Evidently sensitive to the subjectivity of qualitative data, some proponents try to shield themselves with a cloud of useless numbers. ${ }^{46}$ Subjective data are, however, made no more reliable by having more of them.

Not all issues can be answered with empirical data, and of those that can be answered with empirical data, not all can be answered with quantitative data. Anecdotes, expert opinion, and qualitative data are unsystematic data with important roles to play in shaping bankruptcy policy. ${ }^{47}$ But none can give the comprehensive look at debtor and creditor behavior that bankruptcy policymaking requires. Each is limited in the extent to which the data can be generalized; each provides too narrow a view of bankruptcy behavior to form a basis for more than the narrowest policy discussions.

\section{The Difficulty of Using Systematic Data Today}

Systematic data have enormous and obvious advantages over the unsystematic data we have discussed. Systematic data, properly gathered and properly reported, are generalizable, verifiable, and interpretable. Nonetheless, there are difficulties with systematic data, especially episodic data.

As we noted earlier, systematic data come in two varieties: routine and episodic. These differ with regard to their periodicity, the regular or episodic frequency of the collection of data. Regular data collection is typified by census data and unemployment statistics; episodic studies, on the other hand, are funded for particular periods to study particular questions, often with no commitment by grantor or grantee that the study will be repeated.

Regular data are greatly superior to episodic data. Both require expert study design and careful adherence to professional standards; the organizational infrastructure and professional oversight typically associated with regular data gathering make it more likely to be of the highest quality. By the same token, both types of systematic data gathering are expensive, but episodic data, with all their one-time expenses, is necessarily much more expensive per datum. Finally, both varieties of systematic data are subject to abuse, but episodic data are particularly prone to the kind of abuse that is difficult to detect.

46. For a discussion of the silliness of this particular quantification, see Mann, Book Review, 41 WM. \& MARY Q. (3d series) 305 (1984).

47. We call these data "unsystematic" because, in practice, they do not pretend to be comprehensive in terms of time and space. Even within a limited area and time period, such methods do not always attempt to provide a "representative" selection of cases. 


\section{A. Episodic Data Can Provide Only Limited Support to Policymaking}

Most of the systematic data about bankruptcy are episodic, the product of discrete forays into the field on a one-shot basis. The only regularly gathered bankruptcy data are those gathered by the Administrative Office of the Courts, and those data are utterly inadequate for policy purposes. ${ }^{48}$ For most people, including lawyers and policymakers, "empirical data" means data from an episodic study (the guy with the clipboard). In fact, much of the empirical data that are used in policymaking today are regularly gathered data, because episodic data can support policymaking only on narrow issues and to a limited extent. There are two primary reasons for this limitation. First, although systematic data can be greatly superior to unsystematic data, it is difficult for policymakers to evaluate the trustworthiness of such data. This problem is much more serious and intractable for episodic data than for regularly gathered data. Second, aside from the problem of trustworthiness, structural factors ensure that there are never enough episodic data to support policymaking.

1. The Difficulty in Relying on Empirical Data. Systematic data are potentially superior to other varieties of empirical data, but they present pitfalls of their own. Whether systematic data are episodically or routinely collected, risks inhere in how the data are incorporated into the bankruptcy debate. There are some particularly acute risks related to episodic data that serve to limit their usefulness in shaping bankruptcy policy. ${ }^{49}$

Among the problems a policymaker is likely to encounter in trying to use currently available episodic data are (a) inability to cross-examine the data, (b) inadequate access to the data for the purpose of cross-examination, and (c) the risk that the data are being misused. Each of these difficulties makes effective use of the data more problematic and, therefore, increases the potential users' reluctance to incorporate them into the bankruptcy debate.

a. The problem of cross-examination. Engaging in typical doctrinal scholarship in the law library or isolating and confronting normative issues requires energy and intelligence. Incorporating empirical data into one's analysis and conclusions requires all that, plus a new kind of vigilance and-to law-trained scholars-a foreign expertise. The consumer of empirical research, the policy-adviser or policymaker, needs to be able to evaluate the data employed to have some idea of their possible inaccuracies and the appropriate limits on using them.

Because neither legal academics nor legislators usually have much experience with social science methods, they rarely have been trained to

48. See infra notes 83-90 and accompanying text.

49. Analytically, the problems we discuss in this section could be applicable to either episodic or regularly collected data. In bankruptcy, as a practical matter, these problems have a significant effect only in the interpretation of episodic data. In each section we point out why such problems arise with episodic data and how they might be lessened with routinely collected data. 
analyze empirical data in a manner that permits ready challenge. For most, the extent to which one would feel comfortable relying on the data would depend on some vague sense of who compiled them ("professors" sound honest but often disconnected from reality; "industry spokesmen" sound pragmatic but hopelessly compromised) and their size (research on 10,000 bankruptcy cases sounds more likely to yield accurate data than research on only 10). Those trained in legal dialogue are likely to jump to the researchers' conclusions, either dismissing the empirical data as counterintuitive or assuming the conclusions are adequately proven in the unread tables.

When legal academics and legislators encounter empirical data, they frequently do not subject the data to the rigorous challenges with which they examine other evidence. Because they are ill-equipped to cross-examine the data, use of data becomes an act of faith, with a sustaining hope that nothing is seriously wrong with the data and an ever-present suspicion that someone with the social science skills could prove the data useless at any time. This is not an atmosphere likely to make data use a comfortable affair for any policyadviser or policymaker.

Of course, policymakers confront this possibility with any social science data, but we have already pointed out that they regularly incorporate data such as census statistics and unemployment rates into their decisions. ${ }^{50}$ The difference here may be that the perceived neutrality of the regularly collected data-especially data from governmental sources that are regularly reviewed by social scientists-increases confidence in their use. Bankruptcy policyadvisers or policymakers, faced only with episodic data of more eclectic origins, must rely on their own abilities to cross-examine the data. And if they do not feel equal to the task, then use of the data will likely be tentative and sporadic or avoided entirely.

The importance of subjecting empirical findings to the rigorous examination lawyers usually give other kinds of testimony lies in the very nature of the data. No data are provably perfect. Evaluation of data always results in conclusions drawn along a continuum. The data may be more or less "good," depending on how well they satisfy certain criteria. At some point, the quality of the data will be so low as to disqualify their use; in other cases, the quality will be high enough to make the conclusions seem inescapable. More likely, there will be some judgment calls along the continuum. But the data themselves are always vulnerable to the possibility that they do not accurately represent the process portrayed. Their use and the conclusions based on them must be tempered by an awareness of how these data stack up on their own and how they compare with other data.

All data gathering should follow the research methods of a social science discipline-the equivalent of the auditor's "generally accepted accounting principles." This means that the verifiability of the data is enhanced with clear-cut rules for selecting cases, coding variables, and aggregating data.

50. See supra note 5 and accompanying text. See infra note 95 and accompanying text. 
The sampling procedure should be explained with sufficient clarity to permit detection of biases. If questioners cannot be provided copies of the original data, the data analysis should present enough information to allow a reader to judge the quality of interpretation. For example, probability criteria should be presented for statistical tests whenever they are appropriate. ${ }^{51}$

Applying the "generally accepted accounting principles" is not merely mechanical, nor is it straightforward. Those who are familiar with the many tricky problems of application of accounting and auditing principles will fully appreciate the analogous difficulties here. Especially in bankruptcy, where misconceptions persist even among professors of commercial law, a number of pitfalls await the inexperienced who must rely on empirical studies. When the policy-adviser or policymaker is unfamiliar with the origin of the data and cannot rely on the expert scrutiny of the data, then incorporation of empirical data into the bankruptcy debate will remain constrained and peripheral. Data regularly gathered by government agencies in other fields are subject to constant review and monitoring by competent professionals in and out of government. ${ }^{52}$ Episodic data almost never come to the consumer with this safeguard.

b. Data of limited availability. When researchers conduct a study and report on their findings, they may or may not make their supporting data available to those subsequently using the report. Unlike most regularly collected data, especially the data gathered by public agencies, the availability of episodic data varies widely. When empirical conclusions are reported but the supporting data are unavailable for public scrutiny, the problems of crossexamining the data to determine their reliability are compounded. Even if legal academics or legislators were willing to develop the expertise needed to evaluate the data, a great deal of episodic data would not be available for adequate examination.

i. Proprietary data. Research to generate empirical data may be funded from either private or public sources. Where research is funded from public sources, the data generated usually part of the public domain. Researchers generating such data are given a limited period of time to report their findings; then the data must be made available to anyone who requests them. Data generated by private funding, by contrast, are often proprietary. ${ }^{53}$

51. Failing this, the authors should make available to their critics the key information needed to cross-examine the data-for example, tables of means and standard deviations or correlation coefficient matrices.

52. See infra notes 99-103.

53. Systematic bankruptcy data approximate random samples or they represent large portions of a statistical universe of interest. An example of systematic bankruptcy data in the former category is the 1981 survey conducted by the Credit Research Center of Purdue University, which purported to give a view of consumer bankruptcy. Purdue Study, supra note 2. These data, although systematic, are proprietary. The study was paid for by grants from the credit industry, and the resulting data belong to the Credit Research Center. See supra note 83 and accompanying text. The Center may reveal as much-or as little-about the data as it chooses. Neither subsequent researchers nor congressional staffs are able to probe beyond the selected facts and figures that are 
The owners of such data can reveal as much-or as little-as they choose about the data. They may run tests to determine the accuracy of the data, but may only selectively reveal the results of these tests. When challenged about their findings, it is entirely at the discretion of the owners of the data to add to their original findings or to reveal nothing more.

In principle proprietary data may be accurate and reliable, but their quality is often impossible to verify. When they are used in influencing bankruptcy policy, there is no analogue to the litigation concept of discovery. As a result, cross-examining proprietary data is always difficult and usually impossible. Mistakes that may have been made in test design and implementation remain hidden. The only data revealed may be those that support the study's conclusions. ${ }^{54}$ Because proprietary data are commercially collected and disseminated and their accessibility is at the discretion of the owner of the data, the quality of the data can be impossible to test. As a practical matter, it would be too expensive to re-collect privately reported data. Even the analysis and statistical interpretation of the data may be impossible to replicate if the conditions and principles of data collection are shrouded in secrecy.

The problem of verifiability can be circumvented if the data collector is willing to allow others to examine the data. "Examine," in this case, does not mean merely recomputing the formulae to check for arithmetic errors (although even this limited step is often impossible); rather, "examine" implies the possibility of designing new tables from old data, using different statistical techiniques, and introducing levels of statistical controls to test the robustness of findings. Such examinations virtually require that a machinereadable file of data be turned over to other investigators. Without a great deal of cooperation on the part of the original researchers, the verifiability, generalizability, and interpretability of proprietary data cannot be demonstrated.

ii. Practical inaccessibility. Proprietary data are the least accessible, but difficulties inhere even in episodic data collections that are subsequently made public. Confidentiality agreements or other considerations may prohibit making some of the data public. ${ }^{55}$

presented in testimony or are published and distributed by the Center. An example of a data base that represents a large portion of the universe is Mr. Claude Rice's computerized listing of chapter 13 data from a large number of federal judicial districts, but Mr. Rice's data are not episodic because he collects them on a continuing basis. See discussion of Mr. Rice's data, infra note 115 and accompanying text.

54. Apparently true generalizations may, nevertheless, be misleading, such as the well known positive association between storks and the birth rate. Relationships may be modified or even reversed after the statistical introduction of what are called "suppressor" or "distorter" variables. See generally M. Rosenberg, The Logic of SuRVEy Analysis (1968). Tests for distorter or suppressor variables cannot be made with most proprietary data because the entire data base is unavailable for examination.

55. Census data omit not only names and addresses, but also extreme values for such variables as age, income, and selected other items. No geographic area smaller than 100,000 persons can be identified in microdata. (These are data that the user can analyze, developing any desired measures 
Public data, even data gathered by the government, may still be practically inaccessible to the subsequent user. Although government-collected data are for the most part in the public domain, they may not be available in the most convenient or useful form. For example, Administrative Office of the Courts data on bankruptcy are presented by fiscal year, although calendar-year data are more useful for many purposes. Moreover, the categories used are not always the most informative. For example, the business bankruptcies reported by the Administrative Office lump Braniff together with Joe and Ethel's failed diner. The data are designed primarily for calculation of workload averages and reveal nothing of the complexity or substantive nature of the cases. 56

Limited-availability data are difficult to assess in terms of the three criteria we have outlined. Because they cannot be effectively evaluated, their use depends largely on faith in the researchers or on inferences drawn from slim clues about the researchers' techniques. In the bankruptcy area, this has a particularly pernicious effect. There are few data available, and the only currently available large study is of questionable value. This puts the conscientious policy-adviser or policymaker between the proverbial rock and a hard place: Use no empirical data, or use data of highly suspect quality. ${ }^{57}$

c. Deliberate misuse of data. The difficulty of evaluating empirical data and the constraints on the availability of episodic data create yet another intractable problem: The data are too often used in unscrupulous ways. These same evaluation difficulties make it less likely that the unscrupulous user will be caught and increase the reluctance of policy-advisers and policymakers to rely on the data in policy formulations.

The social sciences that produce large amounts of quantitative and qualitative empirical data are fields of highly developed expertise. The conscientious empirical researcher is careful to acknowledge the possibility of normative bias and to work to overcome its confusion with empirical

or tables within the confidentiality constraints.) See U.S. Bureau of the Census, Census of Population \& Housing, 1980: Public-Use Microdata Samples Technical Documentation 3 (1983). These procedures virtually eliminate the possibility of identifying an individual from a census record.

56. Although other data are collected, their publication has been discontinued. See, e.g., ANN. Rep. Of the Director of the Admin. Office of THE U.S. Courts 414-17 (1984) (found in Reports of the Proceedings of the Judicial Conference of the United States) [hereinafter AnN. Rep.]. The problems with the data of the Administrative Office of the Courts are nicely illustrated by their regular publication of a statistical oxymoron, the number of filings of "business chapter 13's." $C f$. infra note 90 .

57. Again, the circularity point can be made. Just as the lack of data discouraged use of the data, and little use of the data discouraged development of more data, the lack of sophistication in dealing with data is reinforcing. If data are rarely used, one can live in relative ignorance with one's professional reputation intact. If data are widely used, however, a greater number of researchers and policymakers may decide that it is as important to understand a test of significance as to be able to work a section 1111 (b) election. As an increasing number of these users become sophisticated in evaluating data and in drawing reliable inferences from the information available, it is not unreasonable to suppose that the quality of the data offered will rise and the role they play in shaping policy will also grow. 
questions and conclusions. The complexity of test design, implementation, and interpretation makes it extremely unlikely that many will retrace the researcher's steps. This underscores the importance of the researcher's adherence to and disclosure of readily accepted research techniques.

The problem goes beyond errors by ineffective actors, who are not peculiar to the social sciences. ${ }^{58}$ When we are discussing the incorporation of the products of social science research, a very different problem emerges: The disingenuous social science researcher can use the cloak of "scientism" to lend greater authority to the work than it rightly deserves. When the data are used for adversarial purposes-when the researcher or the user who have other agendas use the data to "prove" mixed questions of empirical observation and normative conclusions ${ }^{59}$-then the scientist's lab coat (i.e., the charts and graphs, statistical compilations, and scientific jargon) gives the putative findings an aura of respectability they do not deserve.60

This problem is especially acute with qualitative data. Qualitative data raise the issues of subjectivity and value-orientation. Consider, for example, efforts to develop numerical yardsticks for the subjective concepts "good faith" or "ability to pay." The subjectivity objection can be overcome with sufficiently precise definitions applied by well-trained researchers; the resulting data could be generalized. Suppose, for example, that researchers apply a rule that unambiguously defines "good faith" as a seventy-percent dividend to unsecured creditors. The data will be verifiable and generalizable, and the subjectivity objection will generally have been overcome.

As this example illustrates, however, the problem with qualitative data is not just subjectivity; rather, it is also the possible embedding of normative judgments in the data that makes interpretation difficult. In the case of measuring "good faith," critics would argue whether the results of the classification rule are adequately interpreted as the qualitative concept of "good faith." The normative element in interpretation may be overlooked, however, if the characterizations are presented for a large number of cases

58. Our familiarity with ineffective judges, attorneys, and legislators reminds those of us in law of the beams in our own eyes.

59. Earlier we focused on the empirical component of intertwined empirical and normative questions. We noted how difficult it is to separate the two and how legal academics are not in the habit of isolating the empirical from the normative questions. The difficulty under study here is how easy it is deliberately to confuse the formulation of empirical questions with normative questions and to fail to discuss and challenge the normative questions on grounds distinct from the scrutiny accorded the empirical work. The unscrupulous researcher or user asserts that the empirical data answer the normative questions.

60. In reviewing the Purdue study of consumer bankruptcy, we concluded:

The Purdue Study purports to be a scientific study, offering only sterile data . . . Studies like Purdue's are particularly dangerous. They take data with which legislators and lay public are unfamiliar, clothe their work in the robes of scientific research, and attempt to persuade with tainted evidence. The Purdue Study is worse than simply wrong in its conclusions; it takes an approach that is necessary and valuable in the legislative process and perverts it for political ends.

Sullivan, Warren \& Westbrook, supra note 2, at 1145. 
and reported in statistical formats. Aggregating useless data for many cases does not improve their usefulness, but it may obscure their flaws.

The prestige of numbers may lead a researcher to mask the inherently qualitative nature of data with a show of statistics. ${ }^{61}$ False quantification appears to hide the flaws in data that are overtly qualitative, are measured subjectively, or are measured using "objective" categories that incorporate normative concerns. Sophisticated data consumers need to be alert to these abuses as well as to the occasions on which qualitative data are warranted. ${ }^{62}$

The imperviousness of the scientific aura is aided by the reluctance of the nonexpert to cross-examine empirical data for meaning and value. ${ }^{63}$ So long as only the experts are able to question either the scientific methods used or the blending of empirical and normative questions, the adversarial use of inadequate data is relatively risk-free. The presentation of pseudoscientific data to law-oriented audiences is likely to escape the attention of most respectable social scientists. Unless they are called in specifically to review the design and implementation of a study, expert social scientists seldom have reason to read extensively in other disciplines such as law and to notice the uninformed use of substandard research. Even if they did notice, the separation of both the literature and the disciplines generally makes it worth little to the social scientist to make much of a public review of the unacceptable uses.

Another consequence of the unwillingness of the law-trained policymakers to grapple with social science data and to subject the data to vigorous crossexamination is the pernicious effect this failure has on the ultimate usefulness of the data. Without vigorous cross-examination, empirical data remain at the periphery-occasionally seized on for adversarial points and made controlling on some issues, but otherwise largely ignored. This opens the possibility for abuse, but it also undercuts the legitimate uses of the data. Because they are rarely cross-examined and because users are unfamiliar with the data's strengths and weaknesses, empirical data are treated with an unfocused wariness that compromises both valuable and useless data alike.

2. The Dearth of Available Data. Beyond these problems of abuse and uncertainty lies an even more fundamental difficulty: There can never be enough episodic empirical research to develop a coherent picture of what is happening in consumer and business bankruptcies. Bankruptcy policymakers

61. One authority uses the term "statistical doublespeak" to refer to the "inflated, involved, and often deliberately ambiguous use of numbers." D. HAUCK, LITERACY, supra note 29, at 7. For specific discussion of misuse of statistics, see generally S. Campbell, Flaws and Fallacies in Statistical Thinking (1974); M. Wheeler, Lies, Damn Lies, and Statistics: The Manipulation of Public Opinion in America (1976); R. Reichard, The Figure Finaglers (1974).

62. Some authors have provided guides on "statistical doublespeak" for the general public. See D. HAUCK, Literacy, supra note 29, at 294-300. A "checklist" for critical readers is provided by E. Willemsen, Understanding Statistical. Reasoning 210-16 (1974).

63. Again, the analogy to accounting might be helpful. The mysteries of that field can be manipulated to make balance sheets and income statements perfectly plausible but completely misleading. There, as here, it is very difficult for the nonexpert to ferret out the mistakes. 
must currently rely on episodic empirical studies, but there have been very few of them. The only large projects accomplished to date have been studies of 1964 bankruptcy cases by The Brookings Institution and two studies of 1981 cases, one by the Krannert School of Business of Purdue University ${ }^{64}$ and one that we are now completing. ${ }^{65}$ Such projects can be helpful-and they may be essential to providing certain kinds of data-but they can never provide the quality and quantity of data essential to creating an empirical basis for bankruptcy policy.

\section{a. Primary reasons for the lack of data.}

$i$. Expense. The paucity of studies has a number of causes. The first is expense. Collecting data from a sample of cases filed in courthouses scattered about the country involves an enormous amount of travel. The expenses associated with setting up field visits, arranging to ship supplies and equipment, hiring local clerical help and bringing in trained research help, traveling, staying in hotels, eating out, and so forth can make even a modest, one-time proposal run well into six figures. The Brookings Institution's study cost more than $\$ 800,000$, in 1982 dollars, ${ }^{66}$ while the Purdue study cost about $\$ 350,000.67$ Our study will cost more than $\$ 175,000$, plus a large amount of uncompensated time from the researchers, spouses, and students. Each of these three projects-the largest and most complete in the field-studied only a sample of cases from a sample of districts during a single year. The Purdue study and our own are also limited to consumer cases.

ii. The need for interdisciplinary expertise. Gathering and interpreting data from scratch require interdisciplinary expertise if work of any sophistication is to be done. At a minimum, such work requires expertise in the legal field involved and in the methods of social science research.

When we first began our study, a colleague at another school advised us, "You can't just let your research assistant do this; you'll have to look at a couple of cases yourself." We were wryly amused, because at that time we had already logged more than a hundred hours apiece analyzing bankruptcy files in freezing courtrooms. ${ }^{68}$ Our colleague's admonition, however, underscores an important point: Empirical research in bankruptcy is complex. Few areas of statutory law are as difficult as the Bankruptcy Code. Yet, as with any

64. Purdue Study, supra note 2.

65. This study will be published in 1988 by Oxford University Press under the title As WE Forgive OUR Debtors.

66. The study cost more than $\$ 300,000$. Telephone interview with Professor Marjorie Girth (Summer 1986). If we take that amount in 1968 dollars (that year was about the mid-point of the study), it would equal about $\$ 882,000$ in 1982 dollars. U.S. Bureau of the Census, Statistical Abstract of the United States 493, table 809 (105th ed. 1984) [hereinafter Statistical Abstract 1984].

67. Warren, supra note 10 , at 1334 n.5.

68. Among the empirical data we have gathered is the fact that the San Antonio, Texas, federal courthouse in July is kept at an even 61 degrees. We also discovered exactly the number of minutes in a sixty-one degree room it required for each member of the research team to turn a vivid shade of blue. We have not yet run tests of significance of these data. 
statute, the Code is an abstraction of law derived from an even more complicated empirical reality. As a result, the cases it governs are often quite tangled.

Even in a "simple" consumer case, the empirical realities may include dozens of creditors and a host of badly confused financial and legal affairs. Few of these cases reach the appellate level; instead, lawyers and judges hammer out solutions on a day-to-day basis. Further, the image of a unified federal court system that somehow standardizes the process is misleading because of the frequent intrusion of state laws. Even within states, there are often pronounced variations from district to district or even from judge to judge. ${ }^{69}$

Much of the information, although complex, is often repeated and can be usefully compiled and compared. The vast majority of consumer cases fit into well-worn patterns. Nonetheless, abstracting these complexities systematically and reliably into machine-readable format is difficult. Constant and careful communication between lawyer and social scientist is required to devise and execute a collection scheme to discern the routine and to accommodate the aberrational. Failure to unite both legal and social science expertise can lead to results that are uninterpretable at best and seriously misleading at worst. ${ }^{70}$ An attempt to produce a comprehensive study without professional competence in both the law and research methodology encourages an oversimplification in the research design and an interpretation that masks the complexities of bankruptcy practice.

69. Compare the percentage of consumer debtors in chapter 13 in Vermont (5 percent) to the percentage in North Carolina (67 percent). ANN. REP., supra note 56, at 414-17. Compare also the differences within jurisdictions-forty-eight percent filed for relief under chapter 13 in the Eastern District of Pennsylvania, while only seven percent so filed in the Middle District of Pennsylvania; fiftytwo percent filed under chapter 13 in the Southern District of Texas, while only eighteen percent so filed in the Eastern District of Texas; and so on. Id. Further variation may be found in what constitutes "good faith." Some courts have held that good faith is demonstrated by paying unsecured creditors a certain minimum percentage. See, e.g., In re Raburn, 4 Bankr. 624 (Bankr. M.D. Ga. 1980) (seventy percent minimum); Matter of Curtis, 2 Bankr. 43 (Bankr. W.D. Mo. 1979) (ten percent minimum in the absence of exceptional circumstances). Other courts, however, have held that good faith cannot be measured merely by reference to some external standard, but must be determined on the facts of each case. See, e.g. In re Estus, 695 F.2d 311,316 (8th Cir. 1982); In re Goeb, 675 F.2d 1386, 1390 (9th Cir. 1982); In re Rimgale, 669 F.2d 426, 431 (7th Cir. 1982).

70. For example, in the Purdue study, the researchers asserted that the wide variations in the percentage of chapter 13 cases from district to district was the result of certain judges limiting "the petitioner's ability to take a straight bankruptcy unless he or she truly could not repay debts in the specified period." 2 Purdue STUdy, supra note 2, at 103-05. At that time, the judge had no legal right to "impose an informal means test" such as the Purdue researchers posited. The researchers simply assumed that the law conformed to their own conclusions. See Sullivan, Warren \& Westbrook, supra note 2, at 1115-17. Similarly, the Purdue study reports about 21.7 percent of debtors took both state and federal exemptions in jurisdictions that had opted out of the federal alternative, a legal impossibility. 2 PuRdue STUdy, supra note 2, at 96 . Although the Purdue study indicates that both attorneys and nonattorneys worked on the study, separate authorship of the chapters may explain a possible source of the confusion; the only author who indicates a legal background wrote the chapter entitled "Sampling Design and Interview Procedures." 1 Purdue Study, supra note 2, at 17. The other chapters on such topics as "Effect of the Level of Asset Exemptions and Bankruptcy Judges" and "Effect of the Proposed Change in the Federal Bankruptcy Law on Petitioners for Bankruptcy" were written by people on the staff of the Credit Research Center who list no qualifications in law. 1 Purdue Study, supra note 2, at viii; 2 Purdue Study, supra note 2, at viii, 93, 111. 
One approach to this problem is that a legal scholar becomes expert in some social science field, preferably in methodology and statistics. The route to expertise in these areas requires coursework, but the best work is done following an intensive apprenticeship and supervised experience in a number of empirical studies. The personal costs involved in achieving a true expertise in two fields are very high, and very few are willing to pay them. ${ }^{71}$

The other approach is to assemble a team of investigators with the necessary expertise. This approach enormously complicates the task. It is difficult to find and evaluate people interested in the other field. Even within one university, the presence of investigators from different disciplines is likely to increase paperwork and delay exponentially at every stage. ${ }^{72}$ Ironically, the interdisciplinary nature of the work may reduce its academic payoff; 73 colleagues in each field are apt to be more puzzled than impressed that one is mucking about with "them" rather than doing proper work. ${ }^{74}$

iii. Poor scholarship. Another important reason for the lack of empirical data gathered episodically is that it is difficult to attract qualified people to do the work. The gathering of such data involves many cups of stale coffee, late nights in airports, and broken copying machines-exactly the kind of work that legal academics do not enjoy and for which they lack supporting staff. Inevitably, the data collection is a part-time pursuit in the midst of a busy schedule of teaching, administration, and other research. ${ }^{75}$ The work takes years to do, and the academic return in the sense of a measurable number of printed pages is likely to be far lower than if the same time were invested with a number two pencil in the library. ${ }^{76}$

71. One might argue that the difficulty is not that any law professor or social science researcher is insufficiently driven to master two fields, but that it is impossible to maintain state of the art competence in two fields and still have time left over for conducting research.

72. For our own research, in order to apply for outside funding for research generated by both law and sociology faculty, we had to engage in a signature-gathering marathon spanning two schools that took nearly as long to complete as writing the sixty-three-page proposal had taken. We became embroiled in fascinating questions within schools about what level dean or chair in one school was equivalent to what titled dean in another, so that we could have matching authorities. The final delay arose from the need to certify that the law faculty who were involved would still have their offices the following year. The difficulty was not the certification itself (thank goodness). The vexing question was which dean had the authority to make that particular certification, with the ultimate resolution that the correct dean was the assistant dean in charge of assigning offices and secretaries and the like, rather than the dean who might or might not know whether his faculty member would have offices.

73. We have discovered a new mathematical formula to describe interdisciplinary work: (X) (work) $=(1 / \mathrm{X})$ (credit), where $\mathrm{X}$ is the number of coauthors. With three coauthors, this translates into three times the work will yield one third the credit for each researcher.

74. Although our own colleagues were usually much too tactful to raise such questions directly, one of us learned personally of the costs of linking one's professional work too closely with an outsider. The law faculty member was asked to serve on a committee to evaluate all faculty writing and was specifically assigned all papers relating to "anything besides law."

75. In our research, for example, every data trip had to be scheduled around three people, who managed to draw teaching schedules putting at least one of them in class each day of the weekprecisely the same days the courthouses we needed to visit were open. As a result, we struggled with uncomfortable combinations of make-up classes, trading off teaching, and taking trips whenever there was a school holiday.

76. See Getman, Contributions of Empirical Data to Legal Research, 35 J. Legal Educ. 489 (1985). 
One consequence of the difficulty of attracting highly qualified academicians to episodic empirical research is that the field is often left to less qualified people. Empirical legal research sometimes attracts those who have turned to it because they are not very good at traditional work in their own fields. There are fewer with whom they must compete, and their own colleagues are less likely to be able to judge the quality of work when they leave their traditional fields. ${ }^{77}$ Because empirical work is at least as difficult as traditional scholarship, ${ }^{78}$ it is not surprising that the quality of research produced is frequently substandard. Such work gives empirical research a bad name with both academics and policymakers, which, in turn, encourages neither its development nor its use.

iv. Time lag. Another important limitation of episodic research is the time lag between study and publication. Delay is an inevitable consequence of the difficulties of gathering data. There is an achingly long lag between data collection and publication of its analysis. The lag is frustrating to both the producers and the consumers of the data. The Brookings study of 1964 cases was published in 1971.79 Hard and concentrated work was and will be required in our study to publish our analysis of 1981 cases in 1988. The Purdue study did quite a bit better, publishing its 1981 data in $1982,,^{80}$ but its results reflected a focus on early publication of a very selective analysis at the price of accuracy and fairness. ${ }^{81}$

Researchers on empirical projects must live with the fact that they will likely have to invest years in their project before they are ready to report findings and that undertaking a major, systematic research project means committing virtually all of their available time to one project and a group of coauthors. For some researchers, one long empirical project means that a number of other interesting-and shorter-projects must be foregone. These researchers also live with the overriding concern that something may change in that long time period to render their data obsolete. ${ }^{82}$

77. One might also note that even poorly executed work sometimes receives a warm welcome from nontraditional scholars, not because they do not recognize the flaws in the work, but because they want to encourage more people into a sometimes lonely field.

78. For the two of us originally trained only in law and having done our writing in traditional legal scholarship, the empirical work added new dimensions that made the work seem much harder.

79. Brookings Report, supra note 21 , at 222.

80. In addition to the obvious advantages of hiring full-time staff to work on the project, the Purdue study was published only as a typescript monograph. It was not widely distributed to libraries, although it was distributed to influential congressmen through an advertising agency, Ogilvy \& Mather. See Warren, supra note 10, at 1334.

81. See, e.g., Sullivan, Warren \& Westbrook, supra note 2, at 1145-46. Also, see note 100 infra and accompanying text.

82. When we have encountered the inevitable delays in our own project, we have wondered aloud if we should add to the team a legal historian of our acquaintance, since the data may soon be of "merely historical interest." The historian in question strenuously objects to the "merely." 


\section{b. The effects of the lack of sufficient data.}

i. Lack of payoff. There is a fatal circularity in the problem of making empirical research usable in bankrupty policymaking. Each factor that makes episodic research less attractive reinforces the next. For example, a paucity of research means too little is done in any one area to permit either one limited insight to build on another or for a series of related studies to be performed over time, yielding a coherent picture large and detailed enough to satisfy policymakers. Instead, each research product rests on its own, deriving neither factual support nor goodwill from preceding studies. These limitations on how the data may be used reduces policy-advisers' and policymakers' support for such research, and, in turn, the research becomes even less attractive to qualified scholars.

ii. Lack of concrete answers. Even with good researchers, large resources, sensibly framed questions, and a presumptive willingness on the part of legislators to consider the data, episodic empirical research is limited in its ability to shape legislative decisionmaking. Within the limits of resources realistically available, such research will rarely provide definitive answers to policy questions. While the research may cast considerable light on the relevant facts, decisionmakers frequently expect hard, specific answers from empirical data and too often ignore the data completely when they cannot provide such answers. For many policy-advisers or policymakers, the failure of empirical research to yield "useful answers" ends any support for gathering empirical data, and data that are available are ignored. Moreover, their support for research to produce the data is not forthcoming, and the likelihood that additional studies will be done is sharply diminished.

iii. Downward spiral. The circularity in the difficulty of developing empirical data is now complete: Each disincentive to produce systematic, episodic studies compounds other disincentives and magnifies their effects. Because it is time-consuming, expensive, and yields relatively low rewards for the effort expended, little empirical research is undertaken. Because the questions are not framed to highlight their empirical components and both publication and policymaking proceed without embarrassment, research incentives are further diminished. The very lack of data means empirical research is perceived as not very useful, and the incentive to do it is still further reduced. Any one disincentive would have a dampening effect on making empirical research available; the cumulative effects of several disincentives may explain why the number of large systematic studies in a hundred years does not take all the fingers of one hand to count.

On the other hand, the element of reinforcement that perpetuates the current lack of empirical data also offers some hope for the future. As we have noted, lack of data contributes to the nonuse of what we have, which, in turn, is a substantial disincentive to gathering more data. Yet, if data were made available inexpensively and routinely, it is reasonable to suppose they would be more often analyzed and used. If negative reinforcement occurs, 
there is no reason to suppose that positive reinforcement could not also occur. If data were more central to the debate, then demands for more dataand the essential financial support-would generate more research at an increasingly sophisticated level. With a baseline of regularly available data supplemented by an increased number of episodic studies, the data would become more meaningful, which should increase their significance in the policy debate. It is not inconceivable that a useful form of reinforcement could replace the current torpor.

\section{B. Defects in the Regularly Gathered Data We Have Today}

The only bankruptcy data regularly gathered at the present time are of very little value in bankruptcy policymaking. The information published each year by the Administrative Office of the Courts provides only the most gross and superficial picture of bankruptcy filings. ${ }^{83}$ For reasons unknown to us, the amount of information published each year was significantly reduced after June, $1977,{ }^{84}$ in the midst of the furious debate that preceded adoption of the 1978 Bankruptcy Code. Both the decision to withhold data and its timing are puzzling. The result is that much of the data currently collected are not available to academics or policymakers.

The raw data now reported in the annual report of the Administrative Office of the Courts are tabulations originally compiled at the district and division level by the court clerks. We have observed in several courts the preparation of the raw data for these reports. While the clerks who prepare the reports are conscientious, they often encounter unanticipated ambiguities in recording the data; these ambiguities arise in part from the categories into which the Administrative Office subdivides the data.

The principal categories used by the Administrative Office of the Courts are voluntary/involuntary filings; chapter of filing; business or nonbusiness; and stage within the process (for example, "filed," "pending," "terminated"). ${ }^{85}$ These data are cross-classified by circuit and district. ${ }^{86}$ The principal reason for collecting these data, from the Administrative Office's point of view, is apparently programmatic, in that it is concerned primarily with rational allocation of resources and personnel among the districts. For such purposes, the effect of ambiguities in classification is minor. For policy analysis, on the other hand, the ambiguities destroy the value of much of the data. Is a case "terminated" if it is later reopened, an increasingly frequent occurrence with chapter 13 cases?87 Then again, although chapter 13 is

83. E.g., ANN. ReP., supra note 56, at 10-14, 412-19.

84. Previously, the Administrative Office of the Courts had published tables of bankruptcy statistics that included, for example, information about administrative costs and creditor payouts.

85. E.g., ANN. REP., supra note 56, at 412-19.

86. Id.

87. Conversation between Professor Jay Westbrook and Mr. Claude L. Rice, Attorney, McDowell, Rice \& Smith, Kansas City, Kansas (July, 1985). Mr. Rice offers a service that processes chapter 13 files for more than half of the chapter 13 trustees in the United States. See infra note 115. $\mathrm{Mr}$. Rice indicated an increasing trend toward the reopening of chapter 13 cases that had been dismissed. 
usually described as a consumer proceeding, the Administrative Office of the Courts tabulates the occurrence of "business 13's." 88 It is our impression that one clerk may see a "business 13" only where the debtor was a sole proprietor, while a second clerk will find a "business 13" where the debtor's closely held corporation has also gone under, and a third clerk will record a "business 13" if the debtor's employer went out of business. ${ }^{89}$ In terms of the criteria we have outlined, these are issues of verifiability. Such ambiguities prevent our getting a firm fix either on the number of business or nonbusiness debtors or on the direction or degree of changes in business and nonbusiness filings.

For any given year, the Administrative Office of the Courts' data are subject to such variations in meaning. But because the data are presented in standard government nine-point type, year after year, they take on a reality all their own. ${ }^{90}$ At least some researchers have viewed the Administrative Office of the Courts' data as a time series adequate for comparison with the business cycle and other time-bound events. ${ }^{91}$ We are particularly skeptical about such uses. Variations over time in filing rates are difficult to interpret, although facile explanations are offered to explain complex causal relations. ${ }^{92}$ In fact, the year-to-year numbers hide a great many influences, including changes in the federal statutes in 1978 and 1984, changes in the number of states in any one year that have "opted out," 93 changes in lawyer-advertising prevalence and acceptability, and many local events (for example, plant closings or retirement of a particular judge) that may affect filings or terminations.

88. ANN. REP., supra note 56, at 414-17.

89. We noted apparent discrepancies in the designation of cases as "asset" or "no asset" cases; some offices appeared not to make this distinction at all.

90. For example, the bankruptcy clerks classify filings as "business" or "nonbusiness," and the Administrative Office of the Courts reports the cases each year under these headings. Despite efforts to standardize the distinction, it appears that different offices around the country use different tests in practice. This leads to such anomalies as the reporting each year of a number of "business chapter 13's." See, e.g., ANN. REP., supra note 56, at 414-17. There are, of course, a number of cases that are on the boundary between business and consumer bankruptcy. Each time a small proprietor goes bankrupt with both personal and business debts, a judgment has to be made about the classification of his or her bankruptcy. The same problem is created when an individual debtor's bankruptcy follows on the docket sheet immediately after the bankruptcy of the debtor's corporation whose debts he has guaranteed. Different judgments will be made by each clerk's office. It might be desirable to create a third category of cases-perhaps "personal business bankruptcies"-but the main point is the need for precise definitions that can be consistently applied.

91. See, e.g., Shepard, supra note 38, at 431-37.

92. "Econometric results confirm that between 1948 and 1979 personal failure rates were responsive to the increased use of credit by consumers, particularly prior to 1966 , and rising representation of minorities in the population. ... [T] he effects of rising consumer wealth were offset by substantially higher expected levels of government support, a dominant influence in determining failure rates." Id. at 437.

93. When we were working in the East St. Louis, Illinois, federal courthouse on our bankruptcy project, a clerk of the court told us about how hectic it had been at the end of 1980, as attorneys frantically filed their consumer bankruptcy cases to take advantage of the federal exemption before the Illinois "opt-out" would make it unavailable on January 1, 1981. The clerk told of a line of attorneys that "stretched out the courthouse door, down the block and around the corner-all just waiting to file." What impressed us initially about this story was not the implications for statistical distortions, but that the attorneys in the area were willing to stand on a street corner in East St. Louis in December for the relatively modest fees involved in consumer bankruptcies. 
Because many of the legal changes are initiated on a schedule inconsistent with the fiscal-year reporting, the usefulness of the data for many analytical purposes is sharply constrained. In terms of the outlined criteria, these are problems of generalizability and, to some extent, of interpretation. ${ }^{94}$

The failure to develop adequate data does not reflect poorly on the Administrative Office or the bankruptcy clerks, whose efforts give us what little we have. Instead, it is the consequence of failure to design and implement a program for systematic data collection to support policy decisions.

\section{VI \\ Would Regularly Gathered Empirical Data Really Become Important To The Policy Process?}

As we noted at the start, the absence of systematic data in bankruptcy policymaking contrasts sharply with other areas of commercial life in which the use of empirical data is central to the policymaking process. In areas dealing with money supply, trade policy, bank regulation, tax policy, environmental protection, and hospital funding-just to name a fewlegislators routinely rely upon empirical data such as estimated monetary aggregates, unemployment figures, and regional demographic changes. ${ }^{95}$ Indeed, the development and dissemination of such data are so routine, so regularized, and such a constant fixture in the development of policy that they lose their identification as "empirical data" and simply become "facts."

The most obvious contrast between widely used data, such as census information or mortality rates, and bankruptcy data is that the former are gathered regularly, while the latter are generated largely through episodic forays into the field. The data used most often in formulating legislative policy are gathered regularly by government and by private concerns. Economic and trade data, demographic data, and work force data are gathered in America every day of every month of every year. The legislative fields in which data are routinely gathered are precisely the fields in which the fruits of empirical research are an important and routine part of lawmaking.

These widely used data are, of course, not "facts," and treating them as irrefutable does not lead to their best use. The possibility of census

94. Overinterpretation of Administrative Office data is probably inevitable, however, given the paucity of regular data collection on bankruptcy.

95. This is not to say that all legislative decisions that should use empirical data routinely do so. For example, in immigration policy, decisions are made with absent or inadequate data. See generally D. Levine, Immigration Statistics: A Strategy of Neglect (1985) [hereinafter Levine]. But to narrow the point here is also to make it more applicable. It is noteworthy that immigration statistics are not routinely available as part of the continuing policy debate. For examples of the multitude of areas on which statistics are gathered, consult Statistical ABSTRACt 1984, supra note 67, the thirtyseven-page index of which includes entries from "abortion," at 954, to "zoology, degrees conferred," at 991, but does not include "bankruptcy." The thirty-three sections of the volume include separate sections on "Law Enforcement, Courts, and Prisons" and "Banking, Finance, and Insurance," and many sections are devoted to various types of economic data on industries, employment, prices, poverty, etc. 
undercount for blacks has been widely debated in the popular press, the professional journals, and the courts. ${ }^{96}$ Calculation of the Consumer Price Index has drawn increasing attention. Both employers and employees who now have Cost of Living Adjustment (COLA) clauses in their contracts have learned that when the Bureau of Labor Statistics includes some items and excludes certain others, the cost of living index will shift even if the underlying costs did not. ${ }^{97}$ Even the calculation of the current inflation rate in the United States is subject to some dispute. ${ }^{98}$ Notwithstanding their lack of perfection, these data are more reliable than they would be if Congress merely threw a few million dollars at some research agency every once in a while and said "Go count" or "Go check prices." Because the data collection is routinized and subject to constant scrutiny, it is much better than it otherwise would be.

These regularly collected data are the product of research that relies on careful survey design and execution and is more or less accurate and more or less useful, depending on the skills and knowledge of many hundreds of working social scientists. ${ }^{99}$ For most of those data sources, detailed technical documentation is available to alert users to defects and shortcomings. ${ }^{100}$ In addition, data within the federal statistics system are regularly reviewed for adherence to standards of data quality, timeliness, and utility. ${ }^{101}$ Many of the

96. See, e.g., United States Bureau of the Census, Censuses of Population and Housing, 1960: Record Check Studies of Population Coverage (1964); Siegal, Estimates of Coverage of the Population by Sex, Race, and Age in the 1970 Census, 11 Demography 1 -23 (1984).

97. One recent innovation was the development of two indices, one for all urban consumers (CPI-U) and one for all urban wage earners and clerical workers (CPI-W). A second recent change is in the way housing costs are included. Statistical Abstract 1984, supra note 66, at 484 . See generally U.S. Dept. of Labor, Bureau of Labor Statistics, Consumer Price Index, Concepts and Contents over the Years, 517 BLS Bull. (1978).

98. See, e.g., Samuelson, False Signals on Inflation, Newsweek, July 28, 1986, at 47. Mr. Samuelson discusses flaws in the measurement of inflation, including a shift from using home mortgage costs to rental costs just as mortgage rates dropped, to explain why he believes that 1986 inflation rates are overstated. He concludes: "The point is not to condemn the statistics, but to grasp their limits. People who make economic decisions-at the Federal Reserve or anywhere-always steer somewhat blindly. Judgment is necessary and risks unavoidable."

99. For an exposition of the detail and care put into the construction of just one survey, see Herriot \& Kaspryzk, The Survey of Income and Program Participation, in United STates Bureau of the Census, Survey of Income and Program Participation and Related longitudinal Surveys: 1984 , at $169-78(1985)$. The other papers in this collection provide a useful indication of the quality of detailed methodologicl studies of data. See, e.g., Samuhel \& Huggins, Longitudinal Item Imputation in a Complex Survey, in id. at 111-15. (Item imputation is one technique for editing missing information.)

100. An example of technical documentation is United States Bureau of the Census, Census of Population and Housing, 1980: Public-Use Microdata Samples Technical Documentation (1983). This is a 172-page user's guide to data tapes made available from the 1980 Census. The Census Bureau also conducts extensive in-house review of data adequacy and its possible implications. See, e.g., United States Bureau of the Census, Coverage of Population in the 1970 Census and Some Implications for Public Programs, Current Population Reports, Series P-23, No. 56 (1975).

101. One example among many is the comprehensive reviews of labor statistics. See, e.g., National Commission on Employment and Unemployment Statistics, Counting the Labor ForCE (1979); see also Bregger, Establishment of a New Employment Statistics Review Committee, 3 MONTHLY LAB. Rev. 14 (1977) (describing the scope of the National Commission on Employment and Unemployment Statistics: "to identify the needs of the Nation for labor force statistics and assess the extent to which current procedures, concepts and methodology in the collection, analysis, and 
joint federal-state data programs have similar quality controls. ${ }^{102}$ Detailed criticisms in the scholarly literature and ad hoc reviews by panels of experts help insure the integrity of the data. ${ }^{103}$

In other areas of commercial regulation, such as controlling the money supply, adjusting interest rates, or alleviating unemployment, neither Congress nor administrators would conceive of determining policy without a firm grasp of the best available data. Bankruptcy policy, with its enormous economic and social impact, should enjoy the same assumption that the data ought to be an integral part of the decisionmaking process.

\section{VII}

\section{Proposals}

\section{A. Long-Term Proposals: Routine, Systematic Data Gathering and Reporting}

For all the reasons discussed to this point, we do not believe that bankruptcy policy will ever be firmly rooted in reality until empirical evidence about bankruptcy is gathered widely and routinely. Happily, bankruptcy lends itself to this sort of data collection far more than most areas of the law. To gather statistics about ordinary civil litigation is very difficult. Cases come in many varieties, considerable judgment would be required to code descriptions from the files, no regular form can be followed, and various aspects of each case are hard to quantify and harder to compare to each other. ${ }^{104}$ In bankruptcy, by contrast, each file is required by law to contain an enormous amount of important data in a series of standard forms and nearstandard format. ${ }^{105}$ Furthermore, a large number of the consumer bankruptcy cases are sufficiently simple that virtually all the important data can be quantified, coded, and readily compared.

Thus, the information filed initially with each bankruptcy petition is much more like the information on a census questionnaire (which serves as the basis

presentation of such statistics constitute a comprehensive, reliable, timely, and consistent system of measuring employment and unemployment and indicating trends therein").

102. Vital statistics programs are one cooperative federal-state data area. The data are collected by the fifty states with federal assistance. Numerous assessments are made of data quality.

103. A recent example of an extensive critique by an ad hoc panel of experts is LeVINE, supra note 95. The expert panel assessed data collection procedures, quality controls, coordination and duplication of efforts among federal agencies, and automated data processing, and made extensive recommendations to Congress, the Attorney General, the Office of Management and Budget, the Commissioner of Immigration Statistics, the Census Bureau, and other agencies directly involved in the production or dissemination of immigration data.

104. See Kritzer, Studying Disputes: Learning from the CLRP Experience, 15 L. \& Soc. REv. 503 (1981); cf. Jacob, Trial Courts in the United States, 17 L. \& Soc. Rev. 407, 409-13 (1983). In part to try to overcome the difficulties of nonstandardized reporting and wildly varying quantities of information in the court cases involving educational disputes, Michael Revell and Arthur Block developed "caselets" to systematize and summarize their information about the cases. They drew the data for the "caselets" from a variety of sources, including court opinions, key pleadings, briefs, court files, and attorney interviews-an expensive and time-consuming approach. M. REVELL \& A. BLocK, Educational Policymaking and the Courts: An Empirical Study of Judicial Activism (1982).

105. Fed. R. Bankr. P., Official Forms 6-10. 
for some of our most significant economic and demographic data) than like the information in the usual civil litigation pleading. From these schedules can be gathered a great deal of hard information about debtors and their financial affairs. While some debtors no doubt make mistakes (deliberately or accidentally), there are substantial incentives for accuracy: False information is subject to the penalties for perjury and may lead to a denial of discharge. From the information in debtors' bankruptcy files, it would be possible to determine, for example, the general income levels of debtors, the kinds of creditors they have and the amounts they owe to each kind of creditor, whether both spouses have been working in the recent past, the extent to which the debtors have been involved in formal court collection actions prior to bankruptcy, and so on. After the 1984 amendments, it would also be possible to determine the income and expenses for both chapter 7 and chapter 13 debtors and to compare them. ${ }^{106}$

Given the information currently required to be reported, the opportunity exists to gather bankruptcy data routinely and cheaply. If formats as well as forms were standardized for each type of bankruptcy proceeding and attorneys for debtors were required to file forms designed for machinereading, all the basic facts about every bankruptcy case, consumer and business, could be loaded onto computer tapes at a very low cost. ${ }^{107}$ If these forms were properly designed, the process of completing them need be no more expensive or time-consuming than at present; indeed, the present forms are repetitive and confusing, and a "re-form" might well save time for attorneys and debtors, in addition to making the forms machine-readable. So, for example, Form 10, the Summary of Assets and Liabilities, could be omitted, with the computer providing the summary automatically from the other schedules. That step alone might save more time in filling out the forms than the machine-readable format would add.

Some who might be persuaded of the value of our proposal for consumer bankruptcy might be less convinced that it is possible or useful to collect data from business cases. Although it is true that most business cases will involve many postpetition activities that do not lend themselves to mechanical recording, it would, nonetheless, be a great advance to collect the basic data that must accompany every business petition. In addition, it would be helpful to collect at least some "bright line" postpetition data points, such as (a) whether a plan were proposed and confirmed, (b) whether there were an involuntary or voluntary conversion to chapter 7 , and (c) whether the business actually made any payments to its creditors. Moreover, information regarding

106. Bankruptcy Amendments and Federal Judgeship Act of 1984, Pub. L. No. 98-353, \& 302(2), 98 Stat. 333, 353 (1984).

107. Pro se petitioners need not be excluded from this proposal, even though there are relatively few of them. We have identified less than a dozen pro se petitions in our sample of 1500 cases. Pro se petitioners would not necessarily be at a disadvantage in completing a machine-readable form because the general public now uses machine-readable forms in a number of interactions with government agencies and the private sector. The double-checking feature might even improve the quality of pro se petitions. 
these points could be usefully supplemented by including the dates of dismissal or conversion and the amounts of payment to creditors.

In business cases, like consumer cases, the marginal time and cost of rendering the key information in machine-readable form would be minor. As we noted above, our empirical knowledge of business cases is even more primitive than for consumer cases. The development of a data base is, therefore, even more important if those business questions that lend themselves to empirical study are to be identified. Precisely because business cases are more complex and idiosyncratic, they are not easily studied episodically.

A data base that included at least the initial filing information for all business cases would be a giant step forward. For example, Professor LoPucki has done some fascinating preliminary work on the tendency of managements to exhaust the assets of a failing business. ${ }^{108}$ Determination of the next step to be taken in empirical study of the issues he raises would be enormously aided by the presence of a data base showing the assets and liabilities of chapter 11 businesses around the country, by industry, by region, by size of company, and so forth, as well as a comparison of such companies with companies that filed in chapter 7 or converted to chapter 7 after an unsuccessful chapter 11 effort.

Such a data base would help the scholar to identify promising areas of empirical inquiry beyond those made available by the regularized datagathering system. The obvious next step in addressing the questions discussed by Professor LoPucki would be to compare the chapter 11 business with a sample of troubled businesses outside bankruptcy. Because there is currently no available comprehensive information about the businesses that use chapter 11, it would be difficult or impossible to construct a sample of nonbankruptcy businesses that could be usefully compared to chapter 11 businesses. If the proposed data base is made available, the investigator can try to identify patterns in particular industries or parts of the country and then seek a sample of troubled businesses outside of bankruptcy that exhibit some or all of the characteristics that seem to be significant in the chapter 11 businesses. The comparison might yield some important information about the chapter 11 process. Such a data base might not reveal a great deal about Wickes, Texaco, or Continental Airlines, but it would be very helpful in understanding the vast majority of business filings involving less titanic companies. This example illustrates the present difficulty of doing much useful episodic work in business bankruptcy beyond the kind of first step Professor LoPucki has taken, and it suggests the greatly enlarged possibilities that would exist if a national business bankruptcy data base were developed.

This proposal to regularize data collection might even pay for itself if it were made part of a case-management system. If each bankruptcy court were

108. LoPucki, A General Theory of the Dynamics of the State Remedies/Bankruptcy System, 1982 Wis. L. REv. $311-33$. 
supplied with very modest data-processing facilities (perhaps just a couple of business-size personal computers), the data could be made available to everyone in the bankruptcy process (trustees, lawyers, clerks, judges, creditors, and the public) on terminal screens. The routine postpetition formalities of the usual consumer case, including the results of the section 341 meeting and the entry of a discharge, could be entered through a terminal as well. If this were done, we estimate that more than half of the consumer files would never have to be removed from their shelves and would require no additional filing by hand. The elaborate systems of handwritten docket sheets, adversarial cross-references, and the like could then be largely computerized as well. Based on our observations of clerks' offices, the result would be greater efficiency ${ }^{109}$ and a significant improvement in administration. The paper files would remain available for more complex cases and as back-up but could usually be sent to the archives without further reference. The bankruptcy clerk's office might then come to resemble the modern record-keeping office of the late twentieth century and begin to shed its faintly Dickensian air.

Our proposal would also have a salutary effect on the accuracy of the filings. We have found a large number of errors in the completed bankruptcy forms. Although many of them slip through undetected, every error represents a risk of prejudice to the debtor or a creditor, a risk that is realized in some cases. ${ }^{110}$ The machinery used to read the forms under our proposal could be easily set to note apparent anomalies and missing information, so that attorneys could be alerted to reexamine the relevant sections to see if an error has been made. If the bankruptcy system automatically required such double-checking, the quality of the papers filed would no doubt increase dramatically.

As the quality of the papers rose, the reliability of the information given to the court and the creditors would necessarily improve. This change would permit both to make better informed decisions that are more accurate approximations of the enforcement of the rights and duties guaranteed in the Code. Moreover, by making the information readily accessible on a computer programmed to highlight significant information and detect certain typical errors, access to the information in the files would become less haphazard. The potential importance of such a move was driven home to us during our research on the Consumer Bankruptcy Project. In more than a few cases, we encountered files where, on the face of the papers, the attorneys had claimed exemptions well in excess of the statutory limitations, but there was no sign in the closed files that either the creditors or the court had detected the errors and demanded an adjustment. We surmised that the disarray of the files and

109. Greater efficiency does not necessarily imply fewer personnel, but it does mean that court personnel could spend fewer hours each day in transporting files by hand or hand-cart.

110. For example, the authors have repeatedly seen consumer debtors risk losing protected assets because of mistakes in completing forms. 
the difficulties of case management for both courts and creditors permitted errors to slip by unnoticed.

If bankruptcy data were gathered in the manner we have suggested, then summaries and complete copies of the data could be routinely tabulated and sent to the Administrative Office of the Courts for aggregation onto national data tapes. Although bankruptcy files are public, there might be some justifiable concern about misuse of a centralized data base. It would, however, be easy to require that the data received by the Administrative Office be stripped of the debtors' and creditors' names before being processed. The result would be a rich and reliable data base covering the entire country.

The data tapes could be analyzed for a fraction of the expense now required for such studies, and they could be made readily available to creditors' groups, economists, law professors, and other researchers. Congressional staffs, the GAO, and the Administrative Office would have quality data available on a regular and continuing basis.

The availability of reliable and inexpensive data that could be analyzed from the relative comfort of the researcher's computer terminal could have a profound impact on the continuing debates that shape bankruptcy policy. No longer would the only available empirical data be proprietary and controlled by a group that stood to profit from selective exposure of the results. Data would no longer be sporadic, failing to reflect continuing trends. With readily available data, more policy-advisers and policymakers could be expected to discuss some of the data, even if just to mention a fact or two to support an argument. As they did, the circularity we discussed earlier should begin to reverse direction. It would become increasingly difficult to discuss bankruptcy policy while ignoring the data, and some sophistication in dealing with empirical data could become as important as knowing the requirements of a cramdown.

We could also expect the role of the episodic study to change. With regularly collected data made available at cost, episodic studies could concentrate on the collection of other data not routinely available, such as comparisons of bankrupt and nonbankrupt debtors or longitudinal studies on the postbankruptcy impact of filing. These studies could enrich and expand the baseline data available, making them more useful in shaping bankruptcy policy.

With the development of a continuing data base, the usefulness and reliability of episodic studies would be sharply enhanced. With baseline data available, the episodic study would no longer be the isolated foray into the data. As an elaboration of a few better-established empirical points, the episodic study would not need to take on all issues about bankruptcy to be useful. And because the data gathered in the episodic study could be compared to the better known baseline study at least to see if the new data generated bore some reasonable relation to the established data, its evaluation-hence, its reliability-would be enhanced. 
Episodic data could not only expand the scope of data available by asking the questions that could not be included within the routinized collection, but they could also help insure the accuracy of the regularly collected data. As we noted earlier, there are always degrees of confidence with any data, and regularly collected data are not immune from error. One way to enhance the reliability of the data is to check them with occasional episodic studies, to see if different researchers asking slightly different questions in slightly different ways achieve similar results. ${ }^{11}$

Just as we described downward spirals earlier with both the use and the quality of empirical data, here we can describe upward spirals, with the regularly collected data enhancing the quality of the episodic data and the episodic data, in turn, enhancing the quality of the regularly collected data.

The provision of public use tapes of government data is well advanced in other fields, and the debates in those areas reflect the ready availability of the data. Public use samples of the U.S. Census, available for every Decennial Census from 1940 through 1980, have been extensively analyzed by local planners, marketing agencies, advertisers, demographers, and scores of others. Techniques for "secondary analysis" of such data are abundant, yet still developing rapidly. The provision of data to the public has yielded rich insights far beyond what the dedicated but overworked professional social scientists at the Bureau of the Census could provide. There is no reason to suppose that those working in bankruptcy policy and related fields could not do as much. ${ }^{112}$

\section{B. Medium-Term Proposal}

Pending the adoption of a system of regularly gathered bankruptcy data, several things can be done to improve the quality and use of empirical data in developing bankruptcy policy.

111. Examples of how question wordings can lead to different results are provided in K. BaILEY, supra note 22, at 97-98 (double-barreled questions); 98-100 (ambiguous questions); 100-02 (level of wording problems); 102 (abstract versus factual questions); 102.04 (leading questions).

112. For those so inclined, contemplating what could be done with a broad range of bankruptcy data raises exciting prospects for continuing research and analysis with implications far beyond bankruptcy policymaking. With a broad data base, we can move into questions of wider significance in legal analysis, such as developing and testing theories on legal implementation, the role of repeat players in the judicial system, and the limitations of the adversarial model. Bankruptcy, if properly supported with reliable data, can be a fascinating area ideally suited to such studies. In bankruptcy files, more comparable data are available than in any other type of litigation. The combination of some uniform federal provisions and some state variants unique to bankruptcy provide natural laboratories for testing the effects of social and legal variables. The attempts of judges to build a cohesive common law illustrate a process that is common to much of law generally but vastly easier to study in the single-code bankruptcy context. The commercial considerations and social policy concerns woven through the area generate dozens of competing propositions, resolution of which tells us a great deal about our society and our laws. The bankruptcy process-when studied with an ample data base-can be a useful prototype of a legal process studied both for its own sake and to expand our understanding of how laws work. 
One potential source of information is the one-shot, empirical study done from time to time in specific districts or even divisions. ${ }^{113}$ Many of these studies can be done effectively by a student writing a thesis or dissertation, or by a law professor with more curiosity than resources. The problem with these studies is that their origins are so diffuse, their objectives so varied, and their methods so disparate that it is nearly impossible to synthesize their results into larger generalizations.

Similar problems are faced in the empirical social sciences. For example, in psychology, an experiment may be replicated in several sites, or closely related experiments may be conducted in a variety of settings and schools. Each study may have a small and unrepresentative group of experimental subjects (for example, the ubiquitous college sophomore). But if the studies are sufficiently similar in conceptual orientation and if the proper statistics are reported in the published literature, the results can be collected and synthesized by a technique called "meta-analysis."114 Meta-analysts aggregate the findings; if similar results are reported from a large number of studies, then a reliable finding may be reported even if no single study was probative.

If empirical researchers in the bankruptcy area could agree to report certain basic data in every study, no matter how small, they would lay the framework for possible meta-analysis by others. Each study would have to specify the "universe" of the general characteristics of the cases that were eligible for inclusion in the study. Specification of the universe would include time (for example, year of filing, year of discharge, or a similar indicator), place (state, district, division), basis for inclusion (for example, chapter 7 only, all voluntary filings), and method of selecting cases (random sampling, the fattest files, the files that could be found). Certain minimal data would have to be reported, including the number of cases and the means and standard deviations of key variables (for example, secured debts, number of creditors).

If each small case study published contained this minimal information, even in an appendix, other researchers would be able to synthesize the results and draw useful conclusions. The expenditure of time and effort by each individual researcher, even the meta-analyst, would be relatively modest, but the prospective pay-off for the policymaker could be substantial.

113. E.g., Shuchman, New Jersey Debtors 1982-83: An Empirical Study, 15 Seton Hall L. Rev. 541 (1985); Subrin \& Rugheimer, $A$ Statistical Study of Bankruptcy in Massachusetts, with Emphasis on the Bankruptcy Bar and an Examination of the Proposed Bankruptcy Acts, 50 AM. BANKR. L.J. 137 (1976); Yeager, Personal Bankruptcy in the United States with Special Reference to North Western States (1982) (unpublished Ph.D. dissertation, West Virginia University); W. Preston, A Comparison of Rationale and Socioeconomic Characteristics of Straight Bankruptcy and Chapter XIII Petitioners in the Denver, Colorado, Area (1969) (unpublished Ed.D. dissertation, Colorado State College).

114. It is also possible to perform meta-analysis using Chi-square tests based only on frequencies (numbers of cases). Studies that report correlations, $t$ statistics and $F$ statistics can also be used for meta-analysis. See generally G. Glass, B. McGraw \& M. Smith, Meta-analysis in Social Research (1981). 


\section{Short-Term Proposal}

Mr. Claude Rice, a Kansas City, Kansas, attorney, operates a computer service used by about half the chapter 13 trustees in the country. ${ }^{115}$ This service computerizes the chapter 13 payment process and creates records of debts owed, payments made, and so forth. ${ }^{116}$ This data base represents a very valuable source of chapter 13 data. It would be even more valuable if its coverage were documented, if it were fully maintained over a span of years, and if it were made readily available to scholars. As with our long-term proposal, it would be easy enough to ensure confidentiality by eliminating the variables that uniquely identify debtors and creditors before making the data available. Minimal funds would be needed to cover an arrangement between the Administrative Office of the Courts and Mr. Rice to maintain the data and make them public, if he would consider doing so. Indeed, it should be possible to compensate him for entering additional data, beyond what the chapter 13 trustees strictly require, at a relatively minor marginal cost.

The Rice data base requires some further study and analysis before it can be widely used. For example, although it covers fifty percent of the chapter 13 trustees, 117 the districts and trustees that choose to use the system are likely to differ from the districts and trustees that do not, and some of these differences may be substantively important. For example, if districts with relatively few chapter 13 cases do not participate, then the data base will be biased toward high-volume chapter 13 districts. Our research suggests that such districts differ in a number of respects from low-volume chapter 13 districts. In the low-volume districts, debtors who choose chapter 13 are likely to differ in the composition and amount of their debts, assets, and income from chapter 13 debtors in the high-volume districts. ${ }^{18} \mathrm{~A}$ baseline study, although episodic, would help establish the representativeness of the Rice data.

Aside from using the data already gathered, it is important that funding sources be developed to permit further episodic studies prior to a regularization of data collection. Such studies would be anchors to the leeward in the event regularization is not forthcoming. They could also be designed to aid in developing regularization procedures. They would perform the further function of providing comparison data for the initial data made available after regular data gathering begins. Finally, it is important that studies be done to reveal the effects of the 1984 consumer amendments, and such work must not be delayed until a regularized system can be put in place.

115. Bankruptcy Reform Act of 1978: Hearings Before the Subcomm. on Improvements in Judicial Machinery of the Senate Comm. on the Judiciary, 97th Cong., 1st Sess., 579-625 (1975) (statement of Claude L. Rice).

116. Id. at 51-63 (summary of data of chapter 13 cases).

117. Id. at 36 .

118. Sullivan, Warren \& Westbrook, Economic Rationality in the Imperfect World of Consumer Bankruptcy, at Table 10 (prepared for presentation to the American Bar Foundation, February 19, 1987) (copy on file). 
D. Immediate Proposal

The most important intellectual step that should be taken now is the conscious reform of bankruptcy scholarship and debate to insist upon the formulation of empirical questions. We should not continue to accept scholarly analysis or proposals for reform that do not identify the empirical questions raised by the analysis or proposal. While we may be forced to proceed in the courts or in Congress without all the facts we would like to have, there is no excuse for failing to acknowledge those factual gaps.

Confronting the unanswered empirical questions may alter the shape of the bankruptcy policy debate even before the data are forthcoming. Identifying normative questions as such may alter both the tone and the relevant persuasive factors in resolving the issues presented. Moreover, the tenuousness of the debate-its reliance on unavailable empirical observation for resolution-may cause both policy-advisers and policymakers to be more wary of making wholesale changes during the interim.

Finally, if the debates account for the missing data-identify them, highlight them, and suggest caution in proceeding without them-the pressure to develop the necessary empirical data should rise exponentially. If the academic community and the policymakers make it clear that empirical data are an essential part of the policymaking process, then regular datacollection proposals should become a high priority and episodic studies should grow in both number and quality.

VII

\section{ConCLUSION}

We do not imagine that adoption of our proposals will lead to the millenium. We must acknowledge that in those policy areas blessed with a wealth of reliable empirical data, policy mistakes are still made, bad data are sometimes believed, and good data are sometimes ignored. It is axiomatic that every solution creates a new set of problems, and the availability of a large base of empirical bankruptcy data will be no exception.

One subtle difficulty in the policymaking process will be to account for the missing empirical questions. Empirical research not only cannot answer nonempirical questions, it cannot answer all empirical questions. Why debtors go into bankruptcy is an empirical question, but the extent to which empirical research can reliably pin down an answer is very speculative. What it means to a debtor to be in bankruptcy may have some answerable empirical components, but it is very unlikely that all the relevant parts can be exposed and documented by empirical research.

If not all the empirical questions will-or can-be answered with reliable research, then the policymaking process will face a new risk: reliance on available data to the exclusion of important but unknowable empirical factors. The process of gathering data necessarily distorts the debate-the questions we ask are based on what we think we can possibly answer. The policymaking 
debate may run in well-worn channels around what we think we know. If, for example, we know about the number of chapter 11 debtors ultimately converting into chapter 7 but we do not know about the interim effect of the pending chapter 11 on employees, we may seize only on the former and not on the latter in formulating bankruptcy policy.

Nonetheless, the result will be that the debate-and the risks of error-will be on a higher and yet a more concrete plane. The correct solutions may remain unknown, but many apparently plausible answers will be revealed to be palpably wrong. At a minimum, the universe of possible error will be reduced. A mechanism will exist for accounting for the effects of reform and, therefore, some possibility of detecting our mistakes. In short, we will have lit a single candle. ${ }^{119}$

The last decade has seen the emergence of bankruptcy law from a narrow, specialized niche where dwelt a handful of losers in the midst of The Affluent Society. Bankruptcy is now part of the mainstream of American commercial life, and in the turbulence of contemporary economics, it is likely to remain there for the indefinite future. We can no longer operate blindly a system that serves vital functions as part of a multitrillion dollar consumer-debt economy. We cannot continue to guess about the operation of a reorganization scheme that has become a routine part of economic readjustment throughout the country, so that now there is no industry and scarcely a company that has not felt the effects of chapter 11. If bankruptcy is the practice of healing in the law, then it is time for us to leave off bleeding and leeching and launch a systematic program of research.

119. "It is better to light one candle than curse the darkness." Motto of the Christopher Society. 
